\title{
Investigating and Interpreting Failure Analysis of High Strength Nuts Made from Nickel-Base Superalloy
}

\author{
Dallen L. Andrew ${ }^{1}$, Scott S. Carlson ${ }^{2}$, John H. Macha ${ }^{1}$, and Robert T. Pilarczyk ${ }^{3 *}$ \\ ${ }^{1}$ Southwest Research Institute, San Antonio, TX 78238 \\ ${ }^{2}$ Southwest Research Institute, A-10 Aircraft Structural Integrity Program, Hill AFB, UT 84056-5811 \\ ${ }^{3}$ United States Air Force, A-10 Aircraft Structural Integrity Program, Hill AFB, UT 84056-5811
}

Correspondence: D. Andrew. E-mail: dallen.andrew@swri.org

Distribution A: Approved for public release: Distribution is unlimited. Ref \# 2015-02-23_WWA-004

ABSTRACT The United States Air Force experienced failures of three separate zero-time, $220 \mathrm{ksi}$ Inconel 718 nuts that were installed on A-10 aircraft. During the investigation, another nut fracture occurred on an operational jet. This bolt/nut combination had very few service hours on it and was well below the expected service life. A thorough review of the procurement data revealed that all the failed nuts had passed lot tests successfully. This led to concerns that the current procurement test requirements were insufficient to identify nuts that could unexpectedly fail in service. Another factor convoluting the situation was evidence of shanking on one of the four failed nuts. In order to determine the risk for potential future nut fractures, a novel experimental approach was developed and executed to evaluate the strength and integrity for all $220 \mathrm{ksi}$ Inconel 718 nut manufacturers and sizes utilized on the A-10 aircraft. These experiments were designed to have a combination of shanking and pre-load and push the nuts to extreme limits with the intent of uncovering sub-par capability. The amount of torque at failure and the distance traveled by the nut were the two measures of performance. In addition to these experiments, a rigorous metallurgical evaluation was performed to determine if there were any metallurgical anomalies within the fractured and tested nuts. The measured torque values were then used to correlate to the metallurgical evaluations and the results are presented. This novel testing method provided quantitative data to determine the impact of the manufacturing process on the performance of the bolt/nut combination and demonstrated that a characterization of the microstructure alone may not provide evidence of corresponding nut performance.

Keywords structural failures; aircraft failures; threaded fasteners; failure analysis; structural integrity

*Present address: Hill Engineering, Ogden, UT 84404 


\section{Introduction}

When installing a high strength bolt and nut combination, one of the specified geometric constraints is the final thread length of the bolt outside of the nut, often referred to as thread protrusion. This geometric constraint is adjusted by increasing or decreasing the grip length of the bolt and/or the number of washers used between the bolt head/nut and fastened material. Through this installation process it is possible to ensure that the nut is properly threaded on the fastener, ensuring the defined amount of clamp-up torque. If the proper installation process is not followed and too few washers are used (or none at all), it is possible to drive the nut past the threaded region of the fastener and up onto the straight shank of the bolt. This is known as shanking. When the nut is driven up onto this larger diameter, there is a significant potential of rupturing due to the radial expansion. This failure does not require any external loads or forces to exceed the fracture strength of the material. The failure is caused by the strain/displacement induced as the nut is radially expanded around the larger fastener shank diameter. This failure can be instantaneous or be caused in a 'creep-like' manner, either at elevated or lower temperatures.

Fatigue and fracture of the bolt due to improper installation is one of the significant structural problems in fastener tension joints. Typically, bolts have a specified torque requirement to ensure proper joint preload. In fatigue critical joints it is essential that the proper amount of preload is reached during installation to eliminate joint gapping and improve the overall fatigue performance of all the components within the joint [1]. In the situation when the nut is shanked, the required joint preload is not achieved, thus making the joint susceptible to premature fatigue failure. More importantly, the stresses induced in the nut and the associated risk of premature nut fractures compromises the integrity of the joint.

In 2014, the A-10 experienced four $220 \mathrm{ksi}$ Inconel 718 nut fractures. Three of the four nuts fractured post-installation but prior to the component ever being installed on an aircraft and exposed to service loads. One of these nuts exhibited evidence of shanking. The fourth nut fractured in the fleet after limited usage with no evidence of shanking. Nuts manufactured from Inconel 718 were commonly installed on the A-10's new Enhanced Wing Assembly (EWA) and therefore, a clear understanding of the root cause of the failures was critical to support any fleet-wide inspections or part replacements.

During the initial assessments, it was unclear how much shanking had contributed to the failures, given that only two of the four failures exhibited any evidence. Another key factor in the evaluation was that all of the nuts had passed initial quality inspection, lot testing, and procurement specification requirements. Also, all the failed nuts were of one size and were produced by one manufacturer, herein referred to as manufacturer ' $A$ '.

This paper will present the details of the combination of failure analysis, mechanical testing, and experimentation techniques that were used to determine if the $220 \mathrm{ksi}$ Inconel 718 high strength nuts used on the A-10 may be at a high risk for fracture. Results will be provided for all tension tests performed. These tests followed the procurement specification lot testing requirements and reaffirmed that basic tension testing was not sufficient to determine if nuts would fracture post-installation. Failure analysis was performed on a subset of the tested bolts and nuts. These failure analyses included two main phases. The first was fractography, used to determine failure modes and fracture surface morphology. The second main phase of the failure analysis was to perform metallography on failed nuts. The goal of the metallography was to quantify the microstructure, to include grain sizes and phases, with a goal of correlating these material properties to nut performance. This paper will outline some of the limitations of this correlation and highlight the essential nature of mechanical experimentation to understand failure modes and establish risk of failure. In addition, this paper will outline a new 
experimental method used to determine if similar Inconel $220 \mathrm{ksi}$ nuts used on the A-10 ranging in sizes from $3 / 16$ inch to $12 / 16$ inch were susceptible to fracture.

\section{Failure analysis of several initial failed high strength aerospace grade Inconel 718 nuts}

Several new production A-10 EWAs were discovered with axial cracks on Inconel 718 nuts associated with a critical joint requiring large fasteners with high tension capability and consequently high installation torques. These new wings had zero flight hours on them when the failed nuts were identified.

The failed nuts were examined by the USAF 309th Maintenance Wing (MX) Science and Engineering (S\&E) laboratory. In the conclusions from the subsequent failure analysis investigation, the failures were attributed to incorrect installation practices, specifically damage to the threads and sealant in the cracks, with failure resulting from overstress due to over-torqueing or shanking [2]. This type and method of failure is discussed in Section 1.

A few months later, two additional nuts were found failed on other EWAs. After examination, the $309^{\text {th }}$ MX S\&E lab failure analysis report did not attribute the failure to incorrect installation practices but determined these nuts were found to have brittle fracture characteristics [3]. This discovery initiated additional investigations to understand the root cause of the failures. Further detailed failure analysis investigations were completed on the third and fourth nut failures with the root cause being identified as a material embrittlement issue leading to fracture which began at the corner adjacent to the first engaged thread of the nut. The fracture surfaces exhibited brittle morphology near the inner diameter of the nut at the interface with the bearing surface (identified as Location 1 in Figure 1). The brittle morphology features are identified in Figure 2 as Locations 1 and 2, and shown in higher magnification in Figure 3 and Figure 4. There was no evidence of these nuts being shanked during installation, as can be seen by observing the undamaged threads in Figure 5(a), compared to the purposely over-torqued test nut and corresponding damaged threads in Figure 5(b). This new piece of information generated the need to revisit the root cause investigation of all previous EWA nut failures.

Upon further review, the morphology of the fracture surfaces of all the failed nuts in this region exhibited varying degrees of transgranular cleavage and secondary micro-cracks indicative of brittle fracture, as shown in Figure 6 and Figure 7.

These findings indicated an unknown material embrittlement issue causing failures of critical structural parts on a USAF aircraft, resulting in an elevated fleet risk.

\section{Experimental investigations}

In order to understand the risk of these nuts failing on additional aircraft, the failure mechanisms first needed to be understood and quantified. All of the failed nuts were one size (10/16 inch) and produced by manufacturer ' $A$ '. As a risk mitigation action, all of the 10/16 inch nuts from manufacturer 'A' were quickly removed from all EWAs; however, Inconel 718 nuts from the same and another manufacturer (herein referred to as manufacturer 'B'), are scattered throughout the EWA in various sizes, ranging from $3 / 16$ inch to $12 / 16$ inch. The potential failure risk for this population of nuts was unknown. As a result, a robust testing and evaluation effort was developed to address this potential risk. Part of the complexity of the testing was that only the $10 / 16$ inch nut size from manufacturer ' $\mathrm{B}$ ' was available; therefore, relative measures of performance comparing both manufacturers were developed from the 10/16 inch nut tests and then utilized to evaluate the performance and susceptibility of failure of the other nut sizes. The experimental investigation involved three major phases. 
The first phase involved mechanical tension testing to failure in accordance with ASTM F606 [4] of each of the various diameter nut/bolt combinations. The second phase incorporated mechanical torque testing to failure of each of the nut/bolt combinations, in order to replicate a similar loading case on the nuts that was seen in the shanked/failed nuts on the EWA. The third phase focused on evaluating the nuts for possible internal residual stresses induced through the manufacturing process. This was done by slitting them with an electrical discharge machining (EDM) unit and measuring the resulting gap at the slit. In total, there were eight sizes of nuts evaluated (in inches): 3/16, 4/16, 5/16, 6/16, 8/16, 9/16, $10 / 16,12 / 16$. Throughout this article, the numerator is used to designate the size for efficiency: $-3,-4,-$ $5,-6,-8,-9,-10,-12$.

After the experimental phases were complete, fractographic and metallographic evaluations were performed in order to identify and quantify material embrittlement or improper manufacturing issues across all nut sizes and manufacturers. In addition, these evaluations were used to determine if nut performance from the testing could be tied to microstructural information. This would provide critical information that could drive updates to a procurement specification if there was a key manufacturing process in the specification that was not done correctly or potentially not performed at all.

\subsection{Tensile Testing}

\subsubsection{Description}

The objective of the tensile testing was to evaluate and characterize the response of all size fastener/nut geometries under tensile loading. More specifically, the failure load and failure behavior was compared to the specified minimum requirement to identify any differences in load capability or failure type based on manufacturer. As tensile testing was the most straightforward, it was performed first. If tension testing identified that the -10 nuts from manufacturer ' $A$ ' did not meet the strength requirement given by the nut specification, then the other nuts from manufacturer ' $\mathrm{B}$ ' could be tested in the same method for determination of failure. Additionally, if the tests exceed the required strength value and a trend in ultimate tensile strength could be identified based on manufacturer or size, that data could also be used by the USAF to understand the risk associated with all other EWA nuts and take the appropriate risk mitigation actions.

Three fastener geometries were initially selected for testing to include the $-8,-9$, and -10 configuration/sizes. The -8 and -9 geometries consisted of male threads at each end with a collar along the shank. The -10 fastener was a conventional bolt having a 12-pt head on one end and male threads on the other. The required testing loads for all the size bolts and nuts are given in Table 1.

Testing was performed under the guidance of ASTM F606 [4] where it was applicable. Fastener geometries -8 and -9 did not explicitly adhere to the geometries outlined in the standard but the methods described were utilized when testing the samples. For the -8 and -9 configurations, a female threaded adapter was used on one end while the standard ASTM F606 grip was used to secure the end with the nut. The configuration achieved a complete load train and allowed application of a tensile load. An image of this setup is shown in Figure 8. For the -10 configuration (conventional bolt geometry), two ASTM F606 type grips were used with one securing the head of the bolt and the other securing the nut that was threaded onto the male end of the fastener. Testing was terminated upon sample failure.

\subsubsection{Results}


All tensile tests completed (with the exception of a -9 test which was stopped prematurely) exceeded the minimum load requirement from Table 1. There were no observable differences in load capability or failure mode based on manufacturer. Load versus displacement plots for the $-8,-9$, and -10 geometries are provided in Figure 9 through Figure 11. The failure mode was highly consistent across all sizes and manufacturers with the majority of failures due to stripping of fastener threads. One test assembly failed by complete separation of the fastener cross-section.

The tensile testing was discontinued after completion of the initial three fastener sizes. Because there were no discernable differences between manufacturers, from either a failure load or mode perspective, it was determined that additional tensile tests would not provide a method for differentiating nut capability. An alternative method would have to be employed to develop a measure of performance that would identify any differences between nuts from manufacturer ' $A$ ' and ' $B$ '. As a result, torque testing, as described in the following section, was initiated as a next step to differentiate nut capability between manufacturers.

\subsection{Torque Testing}

\subsubsection{Description}

The objective of the fastener torque testing was to evaluate and characterize the response of all nut sizes under torque loading, simulating the installation procedure used on the EWA. During testing, the required objectives/data included: achieving a predetermined torque value, torqueing to failure, and amount of rotation required between the initial target torque and the failure torque value to determine the amount of travel of the nut.

The overall strategy involved establishing an assembly for each fastener size such that a torque could be applied to characterize the behavior of the nut during increasing torque. This was achieved by manufacturing loading blocks that had appropriate sized holes machined in them for fastener insertion. The sizing of the blocks was based on the nut length such that the nut was driven up onto the shank of the bolt a certain amount relative to the nut length and resulted in a 'shanked' condition during torqueing, as well as preloading the entire joint. This was done in order to replicate installation conditions on the EWA. It was critical to develop a test method that would be relative for each size nut. As was previously mentioned, the only size of nuts from manufacturer ' $B$ ' available for destructive testing were of the -10 size. A torque test program would need to be able to induce test failures for both manufacturers and therefore establish a relative comparison between the two, then extend that condition for the additional nut sizes where only manufacturer ' $A$ ' nuts were available.

Torque testing was performed using a calibrated torque wrench. In the case of the -10 and -12 sizes, a torque multiplier (4X) was utilized given the anticipated torque values. An image of the test setup is shown in Figure 12 with a bolt inside the stack up block and a degree map on the top. The degree map was used to document the amount of rotation of the nut, which was then translated into vertical distance traveled by using the number of threads per inch for each size nut.

\subsubsection{Results}

The torque tests, focused on pushing nuts to their strength limits, proved to very valuable when discerning performance of the different nut sizes from different manufacturers. Initially, the -10 nuts from both manufacturers were tested. These tests resulted in nuts being fractured combined with not 
meeting the established minimum torque requirement. The max torque values recorded from the -10 nut failures demonstrated a distinct difference between manufacturer, with the data shown in Table 2 and visually displayed in Figure 13. Two of the four manufacturer ' $A$ ' nuts failed prior to reaching minimum torque, while the other two failed just after reaching the minimum torque. The two manufacturer ' $\mathrm{B}$ ' nuts went significantly past the minimum torque value before testing was stopped (due to the excessive torque value) without any final fractures. It is also important to emphasize that the failures, all from manufacturer ' $A$ ', exhibited the same failure mode (nut fracture) that was observed in fleet failures.

This initial testing provided a clear indication of nut performance based on manufacture. As a result, torque testing was accomplished for all other nut sizes. These follow-on tests resulted in no nut fractures, providing a demonstrated performance difference between the -10 nuts from manufacturer ' $A$ ' and the other nuts tested, and indicated the nut failure risk was isolated to this subset of the population investigated. These findings were critical to assess the scope of the risk for the EWA fleet.

\subsection{EDM Slitting}

\subsubsection{Description}

Relatively large radial gaps between fracture surfaces were observed on the EWA failed nuts discussed in Section 2. Residual stresses within the nut were suspected to be a major contributing factor for the large gaps. As a simple approach to determine if significant residual stresses were present in the nuts, several groups of nuts were slit axially and the resultant gap was measured. The gaps from the slit nuts were then compared to the gaps from the EWA nuts to identify similar behavior/size and if found, more formal residual stress measurement techniques could be performed.

The slitting of the nuts was performed using a wire EDM. Prior to slitting the provided nuts, an index notch was made in a nut fragment left over from previous failure analysis work. This notch on the nut fragment was used to determine the actual width of the wire cutfor the slitting process, which was then applied to the subsequent gap measurements for all nuts. With the assumption that the diameter of the EDM wire was constant, measurements taken on the notch indicated the extra width due to the wire cutting ranged from 0.0028 inch to 0.0041 inch. The obtained average extra width beyond the wire width was 0.0034 inch. Identical power settings and a 0.012 inch diameter wire were used for all cuts. Once the index slot had been made, a single, axially oriented cut was made through the wall thickness of each nut. A fresh length of wire was used for each cut.

For the initial group of nuts, the sectioned nuts were imaged using a calibrated microCT x-ray unit. The nut fragment with the index notch was initially imaged, followed by the slit nuts. After imaging, dimensional measurements were applied to each gap at multiple locations along the length of the gap. All gap measurements were taken at the midpoint of the nut wall thickness. A radiograph of a sample nut is shown in Figure 14. The estimated resolution of the obtained radiograph images is 0.0006 inch.

For the follow-on set of nuts, none of the slit nuts visually appeared to significantly deflect upon slitting and no measurements of the gap were made. A stereomicroscope image of a slit sample nut is shown in Figure 15.

\subsubsection{Results}

When cut, several nuts contracted slightly, resulting in the pinching of the EDM wire. For the initial group of seven -10 nuts (five from manufacturer ' $A$ ' and two from manufacturer 'B'), microCT measurements were taken. Dimensional measurements of the gap widths of the slit nuts corroborated the 
observation that several nuts contracted upon being cut. Accounting for the extra width of the cut due to the slitting process and based on the maximum diameter of the EDM wire, the estimated expansion of this gap was 0.0018 inch on a manufacturer ' $A$ ' -10 nut and 0.0017 inch on a manufacturer 'B' -10 nut, which are both significantly less than the approximately 0.06 inch to 0.10 inch gap found on one of the EWA nuts. There was no significant difference in the amount of expansion exhibited by the nuts from the different manufacturers.

Metallographic examination of the slit nuts revealed that the -10 nuts exhibited some limited variability in grain size, but generally displayed equiaxed grains with no evidence of banding. Observed delta phase precipitates exhibited an acicular morphology and were located predominately at the grain boundaries, as seen in Figure 16. The equiaxed microstructure exhibited by the -10 nuts would be expected to lack the short range microresidual stresses associated with the grain size variation inherent in a heavily banded microstructure.

Since none of the slit nuts from either manufacturer exhibited as large a gap as observed by the USAF on the failed EWA nuts, the conclusion was that internal residual stresses were not a significant driving factor for the EWA nut failures.

\section{Failure Evaluations}

\subsection{Fractography}

\subsubsection{Description}

Fractographic analysis was performed on four -10 nuts from manufacturer ' $A$ ', as these were the only nuts that fractured as a result of testing. The fracture faces were evaluated to identify any signs of brittle fracture morphology and possible associated material processing problems. The goal was to identify any correlation between fracture morphology and testing performance of the nut, i.e. quantifying an area of brittle fracture that could be used to relate to the torque testing results and, therefore, be tied to manufacturer ' $A$ '. The fracture morphology of the nuts was also qualitatively compared to the previously examined nuts which had failed in service.

Each fracture surface was initially examined using a stereomicroscope to identify the approximate fracture origin location and the direction of fracture propagation. Scanning Electron Microscope (SEM) imaging was used to examine fine features of the fracture surface at the origin. An example of an SEM montage put together for one nut is given in Figure 17.

\subsubsection{Results}

In summary, brittle fracture features and microcracking observed on the failed EWA nuts in the corner regions adjacent to the first engaged threads (see Location 1 in Figure 18) were not as prominent on the nuts failed during the experimental testing at comparable magnifications. Some amount of qualitative information was gathered from comparing the fractography of the EWA nuts to the experimental nuts, but no real quantitative information was identified to relate to the risk of failure of the nut based on manufacturer.

Of the four -10 nuts which fractured due to the experimental torque tests, samples $-10 \mathrm{~N} 3 \mathrm{a},-10 \mathrm{~N} 4$, and $-10 \mathrm{~N} 5$ each exhibited fracture features consistent with a fracture origin located at the outer diameter of the nut opposite the threads, near the wall thickness transition region close to the 
base at the flat of the nut, such as Location 2 in Figure 18. The stereomicroscope image provided in Figure 19 shows the origin location on the fracture surface of sample-10N3a. Faint chevron markings indicated the fracture origin of sample $-10 \mathrm{~N} 3$ was near the inside corner of the nut adjacent to the first engaged thread, at a location similar to the nuts which failed in service (Location 1 in Figure 18). SEM imaging of the fracture origin sites of three of the -10 size EWA fleet nut failures compared to one of the manufacturer ' $A$ ' torque test nut failure samples are shown in Figure 20. These images reveal mixedmode fracture features at the origin, in contrast to the predominately brittle fracture features exhibited by the origin regions of the three -10 nuts which failed in service. Fractographic analysis clearly indicated significant differences in fracture origin location and morphology between the experimentally failed nuts and the field failure nuts, thus not giving a quantifiable value to distinguish between manufacturers.

\subsection{Metallography}

\subsubsection{Description}

The objective of the metallographic evaluation of the mechanically tested nuts was to determine if the variations in nut breaking strength observed in the test results could be correlated to differences in microstructural features of the nuts and, therefore, to a specific manufacturer. Specifically, the nut microstructures were evaluated for grain size variation, the presence of banding, and the relative volume and location of delta phase. Both solid solution and precipitation are significant strengthening mechanisms for Inconel 718, with the primary precipitation strengthening occurring by the formation of the gamma double prime and gamma prime phases [5]. In the wrought form, melt-related issues such as macro-segregation and the formation of intermetallic phases can lead to significant variation in the mechanical properties of forged parts [6]. An additional precipitate present in Inconel 718, delta phase, is generally detrimental to mechanical properties [7]. Delta phase does not contribute significantly to the hardenability of Inconel 718, and the presence of excessive delta phase implies a loss of hardenability due to the corresponding depletion of the gamma-double prime phase [8]. The presence of delta phase in Inconel 718 has also been associated with an increased susceptibility to hot cracking [9]. Delta phase generally exhibits an acicular or platelet geometry [10]. Intergranular fracture observed in rupture testing of Inconel 718 specimens has been attributed to the incoherent interfaces formed by delta phase on grain boundaries $[11,12]$.

Combinations of $-8,-9$, and -10 nuts which had been previously subjected to mechanical tension or torque testing were received for sectioning and metallographic evaluation. Each nut was sectioned in the axial direction, mounted, and mechanically polished. All samples were electrolytically etched in a solution of hydrochloric acid and glycol and examined in a light microscope. Selected samples were investigated at high magnification in a SEM to examine fine microstructural features.

\subsubsection{Results}

Of the evaluated -8 nuts which were subjected to torque testing (all from manufacturer 'A'), the cross-sectional microstructures of the majority of the samples were similar, exhibiting equiaxed grains, no significant banding, and limited grain size variation in the flat end of the nut. The microstructures of samples $-8 \mathrm{~N} 1,-8 \mathrm{~N} 3$, and $-8 \mathrm{~N} 6$ (tension test, manufacturer 'A') samples exhibited more variation in grain size, but no significant banding compared to the EWA nuts which failed in service. Figure 21 and Figure 22 show light micrographs of the corner region of sample $-8 \mathrm{~N} 3$, which exhibited a typical microstructure representative of these samples. 
A significant amount of microstructural variation was observed in the $-9 \mathrm{~N}$ size nuts which were subjected to tension tests (all from manufacturer ' $A$ '), but no banding was observed. Of the -9 nuts subjected to torque testing, most did not exhibit banding. Samples -9N6, -9N7, and -9N8 (manufacturer 'A') exhibited fine, uniform grains similar to the -8 nuts throughout their microstructures, with visible flow lines from the forging process. Nuts $-9 \mathrm{~N} 7$ and $-9 \mathrm{~N} 8$ also exhibited a number of enlarged grains near the mid and lower regions of the flat end of the nut. Figure 23 and Figure 24 show light micrographs of the grain size variation of nut $-9 \mathrm{~N} 8$, which resulted in a banded appearance.

The microstructures of the tensile test samples $-10 \mathrm{~N} 1,-10 \mathrm{~N} 2$, (manufacturer 'A') and -10N6 (manufacturer 'B') exhibited some limited variability in grain size, but were generally consistent with the morphology previously observed on a failed EWA nut. These samples exhibited equiaxed, uniformly sized grains with no evidence of banding. Delta phase needles were short and tended to be concentrated along grain boundaries. The typical corner region microstructural morphology of these samples is shown in Figure 25. The microstructure of the -9N2 nut, which was the single test setup to exhibit a fastener failure, did not appear significantly different compared to the microstructures of the nuts which failed due to shearing of the threads.

Of the torque test nuts examined, sample $-10 \mathrm{~N} 4$ exhibited a microstructure very similar to the $-10 \mathrm{~N}$ tension test samples, with fine, equiaxed grains, no banding, and very limited grain size variation. Both samples -10N3a and -10N5 exhibited obvious banding caused by pronounced grain size variation. Longer delta phase needles were preferentially clustered within the large grains. The corner microstructure of Sample -10N5 is shown in Figure 26.

High magnification SEM imaging of selected nut cross sections revealed the same general fine-scale distribution of delta phase was consistent across the different nut sizes. At locations exhibiting little or no banding, the delta phase platelets were short and generally sited singularly or in rows along grain boundaries, as seen in Figure 27. At locations exhibited banding and grain size variation, intragranular nucleation of delta phase platelets was more frequently observed, as shown in Figure 28.

Because of the variation found in the metallographic features found within manufacturer ' $A$ ', it was impossible to make a distinguishing observation between manufacturers ' $A$ ' and ' $B$ ' based on metallographic features alone. One clear finding was metallographic inconsistency in manufacturer ' $A$ ' nuts compared to the apparent metallographic consistency in manufacturer ' $\mathrm{B}$ ' nuts. While a correlation could not be made between the observed microstructural features and the performance of the nuts in the torque test, the anisotropy and increased presence of delta phase needles in banded regions would be expected to negatively impact the local mechanical properties of the affected nuts in a variety of loading situations. The extensive banding exhibited by the field failure nuts near the fracture origins is consistent with the brittle fracture observed at those locations, given the influence of grain size on the initiation and propagation of brittle fracture. However, no evidence of brittle fracture was present on any of the torque test nuts, including those which exhibited a banded microstructure.

\section{3 $\quad$ ASTM Grain Size Estimation}

Following the metallographic examination, the grain size of the corner region was estimated on most of the samples. The estimations were made based on the intercept method outlined in ASTM E112 [13], using micrographs of the etched cross-section. The results are summarized in Table 3, which shows that the estimated grain size near the corner ranged from 9-11 for the -8 samples, 9.5-12.5 for the -9 samples, and from 10-11.5 for the manufacturer ' $A$ ' -10 samples.

When the microstructure from the manufacturer ' $A$ ' -10 nuts were visually compared to the microstructure from a manufacturer ' $\mathrm{B}$ ' -10 nut, as shown in Figure 29, the difference in microstructure 
was readily apparent with manufacturer ' $\mathrm{B}$ ' nut microstructure noticeably smaller. This observation correlates to the difference in performance based on manufacturer observed during the torque testing. However, because of the relatively large variation in grain size for manufacturer ' $A$ ' nuts, a comparison of grain size as an indication of performance for all other sizes was not possible. As seen in Table 2 and Table 3, the two nuts from manufacturer ' $A$ ' which failed below the stated minimum torque value had measured ASTM grain sizes of 10 and 11.5, which represents the entire range of ASTM grain sizes observed in the -10 nuts from manufacturer ' $A$ '.

\section{Summary}

As part of a root cause investigation of the EWA nut failures, nuts of sizes from 3/16 inch to 12/16 inch made by several manufacturers were tested and evaluated to determine if there was a correlation between nut size, manufacturer, and performance.

ASTM F606 tension tests were completed for the $-8,-9$, and -10 sizes with no nut failures occurring. As a result, no additional tensile tests were completed. All tensile tests met the required minimum load so there was no ability to correlate between maximum load capability and manufacturer.

Five torque tests for all sizes were completed. This information was used to compare behavior between nuts from the different manufacturers. The -10 size nuts from manufacturer ' $A$ ' were the only size to see both nut fracture and not meet the minimum required torque. The max torque value recorded from the -10 nut failures showed that there may be a relation between manufacturer and max torque. Two of the four manufacturer ' $A$ ' nuts failed prior to reaching the minimum torque value nut with all four being fracutred, while the two manufacturer ' $\mathrm{B}$ ' nuts went significantly past the minimum torque value before testing was stopped without a fracture.

Seven un-tested nuts pulled from actual EWA aircraft and the nine tension test nuts were slit via EDM wire and inspected for gap expansion/contraction which would be caused by internal residual stresses developed during manufacturing. It was hypothesized that the fleet failures may have been caused by a combination of residual stress within the nut and loading during installation. These tests were to provide a general idea of whether or not there were significant residual stresses within the nuts. The maximum gap expansion observed from all of the slit nuts from either manufacturer was approximately 0.0018 inch, which was an order of magnitude less than the gap observed in the failed nuts from the EWA fleet, which had a gap of approximately 0.06 inch to 0.10 inch. The measured gap for all 16 slit nuts was considered minimal and demonstrated that residual stresses developed during manufacturing was not a significant factor in the slit nuts and therefore not a significant factor in the EWA fleet fractures.

It was observed from the -8 and -9 metallography that some of the manufacturer ' $A$ ' nuts showed extensive delta phase along the grain boundaries while other nuts showed little delta phase along the grain boundaries. This was observed for nuts within the same lot. As all the -8 and -9 nuts met the minimum required torque without nut failure, it is concluded that the microstructure alone was not able to give definitive evidence of corresponding nut performance. This conclusion was based on the results from the different -8 and -9 lots that were used in the torque tests, where all nuts met the required torque, unlike the -10 tests, where some of the manufacturer ' $A$ ' nuts did not meet the required torque value.

\section{Conclusions}


There is often an attempt to determine performance of materials/parts from failure analysis and standardized tests. When these two forms of material evaluation cannot replicate failures observed in the fleet, additional testing and evaluations may be needed to simulate more representative conditions.

This paper provided an overview of a testing and materials evaluation to quantify the risk for a range of high-strength Inconel 718 nut sizes when failures were observed in only one nut size. The work outlined in this paper demonstrated that failures observed within manufacturer ' $A$ ' -10 nuts did not represent the performance capabilities of the other manufacturer and nut sizes. The novel testing approach demonstrated that the risk was isolated to the -10 nut size produced by manufacturer ' $A$ '. These findings were critical to effectively manage the safety of the EWA fleet. Consequently, an EWA fleet -10 nut replacement program was initiated to remove and replace all -10 nuts from manufacturer 'A', and no additional steps were taken to develop a nut replacement plan for any other sizes.

Funding: This work was performed under contract with funding provided by the United States Air Force. 


\section{REFERENCES}

1. Minguez, J.M., Vogwell, J., (2005). Theoretical analysis of preloaded bolted joints subjected to cyclic loading, International Journal of Mechanical Engineering Education, Vol. 33, Issue 4, pg. $349-357$.

2. Materials Laboratory Report 11289-13, "Nut, A-10 MLG Outboard Mount Attach, PN: ST3M572-10M”, United States Air Force, 809 ${ }^{\text {th }}$ MXSS/MXDEA, Hone, C., July 2013.

3. Materials Laboratory Report 11515-14, "Nut, A-10 MLG Outboard Mount Attach, PN: ST3M572-10M," United States Air Force, 809 ${ }^{\text {th }}$ MXSS/MXDEA, Hone, C., January 2014.

4. ASTM F606-13, Standard Test Methods for Determining the Mechanical Properties of Externally and Internally Threaded Fasteners, Washers, Direct Tension Indicators and Rivets, ASTM International, West Conshohocken, PA, 2014.

5. G. Appa Rao, Mahendra Kumar, M. Srinivas, D.S. Sarma, "Effect of standard heat treatment on the microstructure and mechanical properties of hot isostatically pressed superalloy Inconel 718" Materials Science and Engineering A355 (2003) 114-125.

6. S.T. Weldek, R.D. Fielder, in: E.A. Loria (Ed.), Proceedings of the Conference on Superalloys 718, 625 and Various Derivatives, TMS, Warrandale, PA, 1994, pp. 167-176.

7. Saied Azadian, Liu-Ying Wei, Richard Warren, "Delta phase precipitation in Inconel 718," Materials Characterization 53 (2004) 7- 16.

8. Azadian, S., Wei, LY, Niklasson, F., Warren, R., Precipitation in spray-formed IN 718. In: Loria EA, editor. Superalloys 718, 625 and various derivatives. Warrendale, PA7 Minerals, Metals \& Materials Society; 2001. p. 617-26.

9. Lu O., "HAZ Microstructural evolution in alloy 718 after multiple repair and PWHT cycles," PhD thesis, Ohio State University, Ohio, United States; 1999.

10. Sean Gribbin et al. "Low cycle fatigue behavior of direct metal laser sintered Inconel alloy 718," International Journal of Fatigue, Volume 93, Part 1, December 2016, Pages 156-167.

11. C.-M. Kuo et al. "Aging effects on the microstructure and creep behavior of Inconel 718 superalloy,” Materials Science and Engineering A 510-511 (2009) 289-294. 
12. W. Chen and M.C. Chaturvedi, "Dependence of creep fracture of Inconel 718 on grain boundary precipitates,” Acta materialia.Vol. 45, No. 7, pp. 273\$2746, 1997.

13. ASTM E112-13, Standard Test Method for Determining Average Grain Size, ASTM International, West Conshohocken, PA, 2014.

14. SAE Aerospace, (2012). Areas for Calculating Stress or Load Values for Externally and Internally Threaded Fastener, Spec Number AS5054, Rev. A, SAE International. 


\section{Tables}

Table 1: Required load for ultimate strength of nut for all sizes compiled from [14]

\begin{tabular}{|c|c|}
\hline $\begin{array}{c}\text { Coupon } \\
\text { Designation }\end{array}$ & $\begin{array}{c}\text { Axial Tensile Strength } \\
\text { (minimum lbs at room temperature) }\end{array}$ \\
\hline-3 & 4,970 \\
\hline-4 & 8,870 \\
\hline-5 & 14,100 \\
\hline-6 & 20,900 \\
\hline-8 & 37,800 \\
\hline-9 & 47,900 \\
\hline-10 & 59,900 \\
\hline-12 & 86,900 \\
\hline
\end{tabular}

Table 2: Summary of torque test results for $\mathbf{- 1 0}$ size nuts

\begin{tabular}{|c|c|c|c|c|c|}
\hline Test Article \# & Manufacturer & $\begin{array}{c}\text { Torque } \\
\text { Required } \\
\text { (inch-lbs) }\end{array}$ & $\begin{array}{c}\text { Torque Max } \\
\text { (inch-lbs) }\end{array}$ & \% of min & Fractured? \\
\hline$-10 \mathrm{~N} 3$ & A & 2880 & 3648 & $126.7 \%$ & Yes \\
\hline$-10 \mathrm{~N} 3 \mathrm{a}$ & $\mathrm{A}$ & 2880 & 2576 & $89.4 \%$ & Yes \\
\hline$-10 \mathrm{~N} 4$ & A & 2880 & 3260 & $113.2 \%$ & Yes \\
\hline$-10 \mathrm{~N} 5$ & A & 2880 & 2624 & $91.1 \%$ & Yes \\
\hline$-10 \mathrm{~N} 7$ & B & 2880 & 5484 & $190.4 \%$ & No \\
\hline$-10 \mathrm{~N} 8$ & B & 2880 & 4360 & $151.4 \%$ & No \\
\hline
\end{tabular}


Table 3: Corner region grain size estimations

\begin{tabular}{|c|c|c|}
\hline Sample & $\begin{array}{l}\text { Average measured intercept } \\
\text { distance }\left({\mathrm{x} 10^{-4}}^{\mathrm{inch}}\right)\end{array}$ & ASTM Grain Size \\
\hline$-8 N 2$ & 3.50 & 10.5 \\
\hline$-8 N 4$ & 2.80 & 11 \\
\hline$-8 \mathrm{N5}$ & 5.87 & 9 \\
\hline$-8 \mathrm{N7}$ & 5.63 & 9 \\
\hline$-8 N 8$ & 5.67 & 9 \\
\hline$-9 \mathrm{N1}$ & 2.64 & 10.5 \\
\hline$-9 \mathrm{~N} 2$ & 1.85 & 12.5 \\
\hline$-9 \mathrm{N3}$ & 2.68 & 11 \\
\hline$-9 N 4$ & 2.91 & 11 \\
\hline -9N5 & 4.92 & 9.5 \\
\hline$-9 \mathrm{N6}$ & 2.01 & 12 \\
\hline$-9 N 7$ & 2.01 & 12 \\
\hline$-9 N 8$ & 2.05 & 12 \\
\hline$-10 \mathrm{N3}$ & 2.80 & 11 \\
\hline$-10 N 3 a$ & 4.09 & 10 \\
\hline$-10 N 4$ & 2.32 & 11.5 \\
\hline$-10 \mathrm{N5}$ & 2.09 & 11.5 \\
\hline
\end{tabular}




\section{Figures}

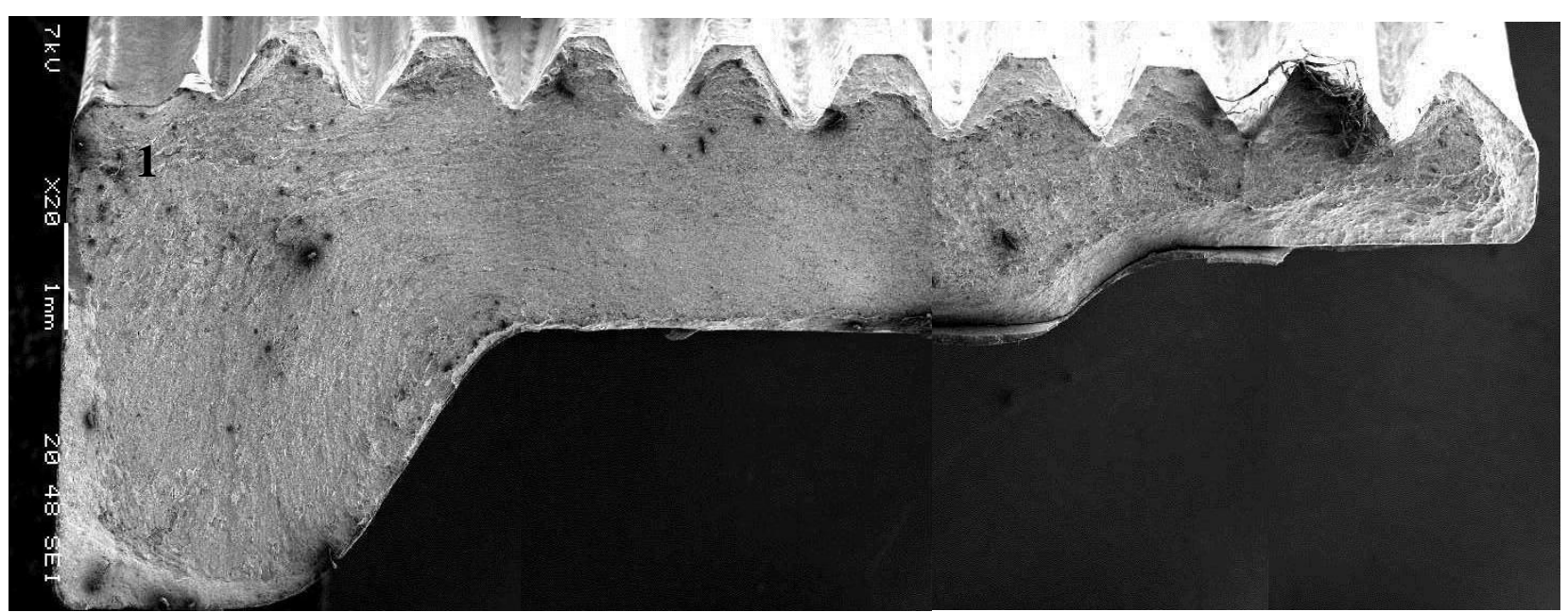

Figure 1: Composite of SEM micrographs showing fracture surface topography for the failed EWA nut from [3] 


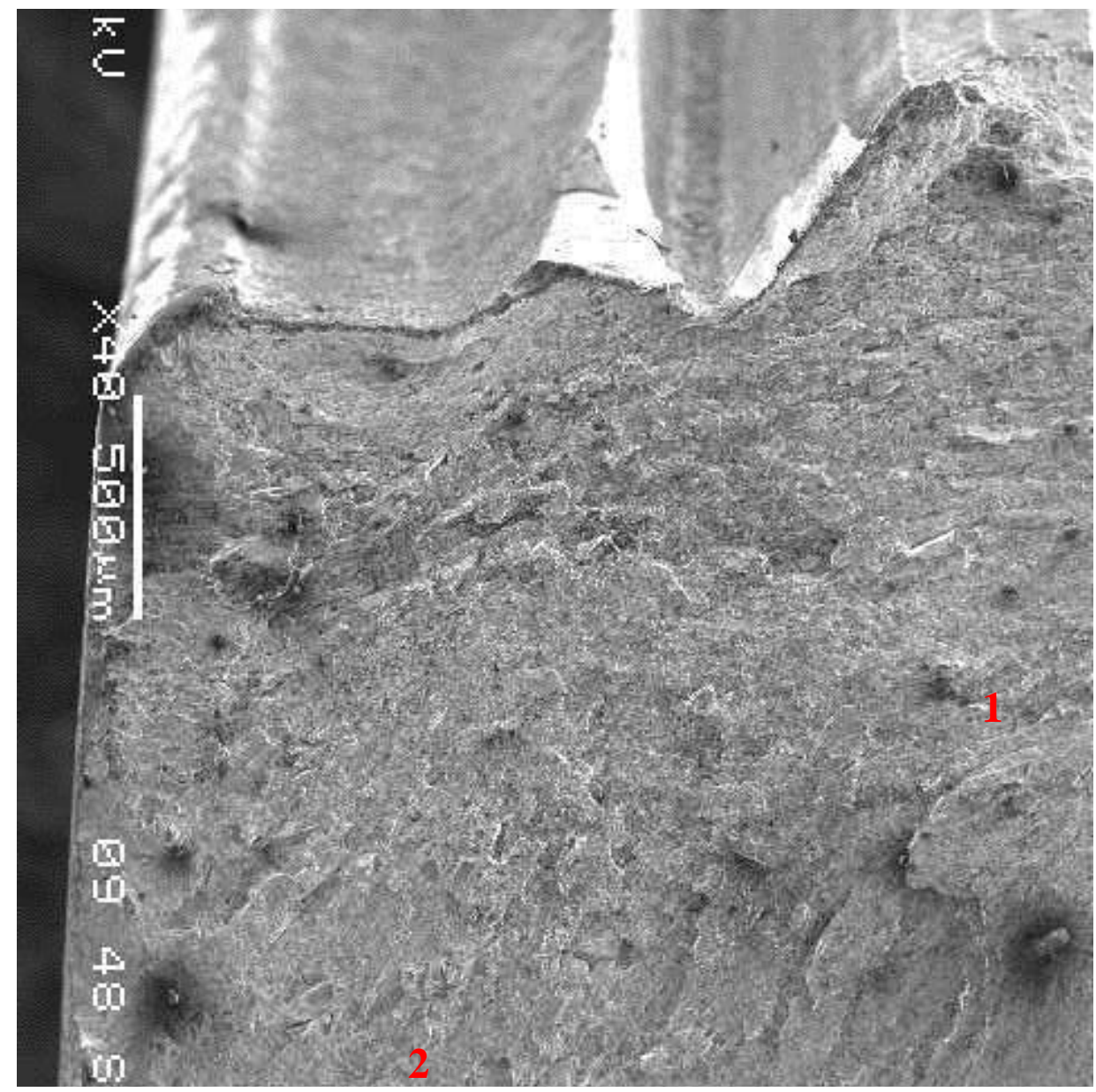

Figure 2: SEM micrographs showing fracture surface topography in corner region Location 1 in Figure 1 for the failed EWA nut from [3] 


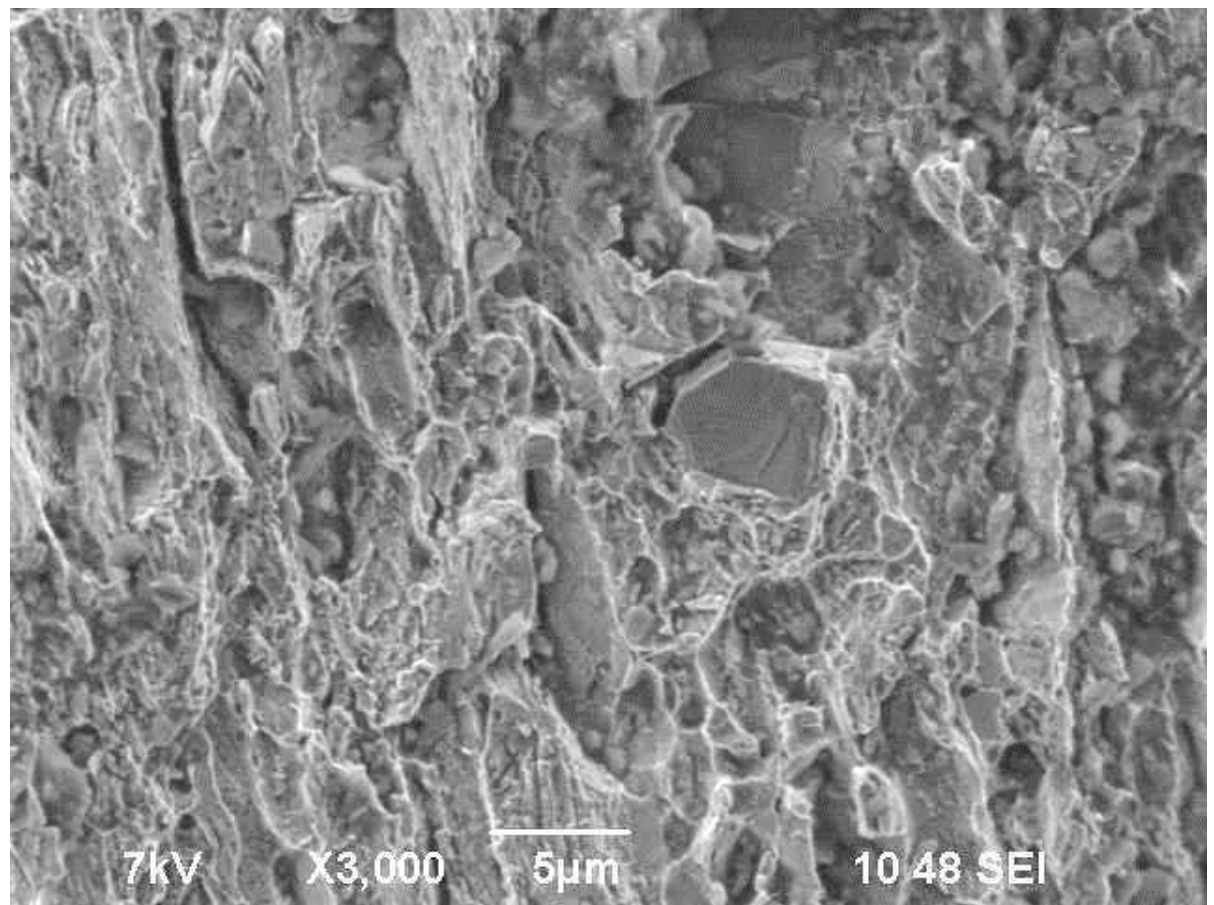

Figure 3: SEM micrograph showing mixed mode fracture at Location 1 in Figure 2 for the failed EWA nut from [3]

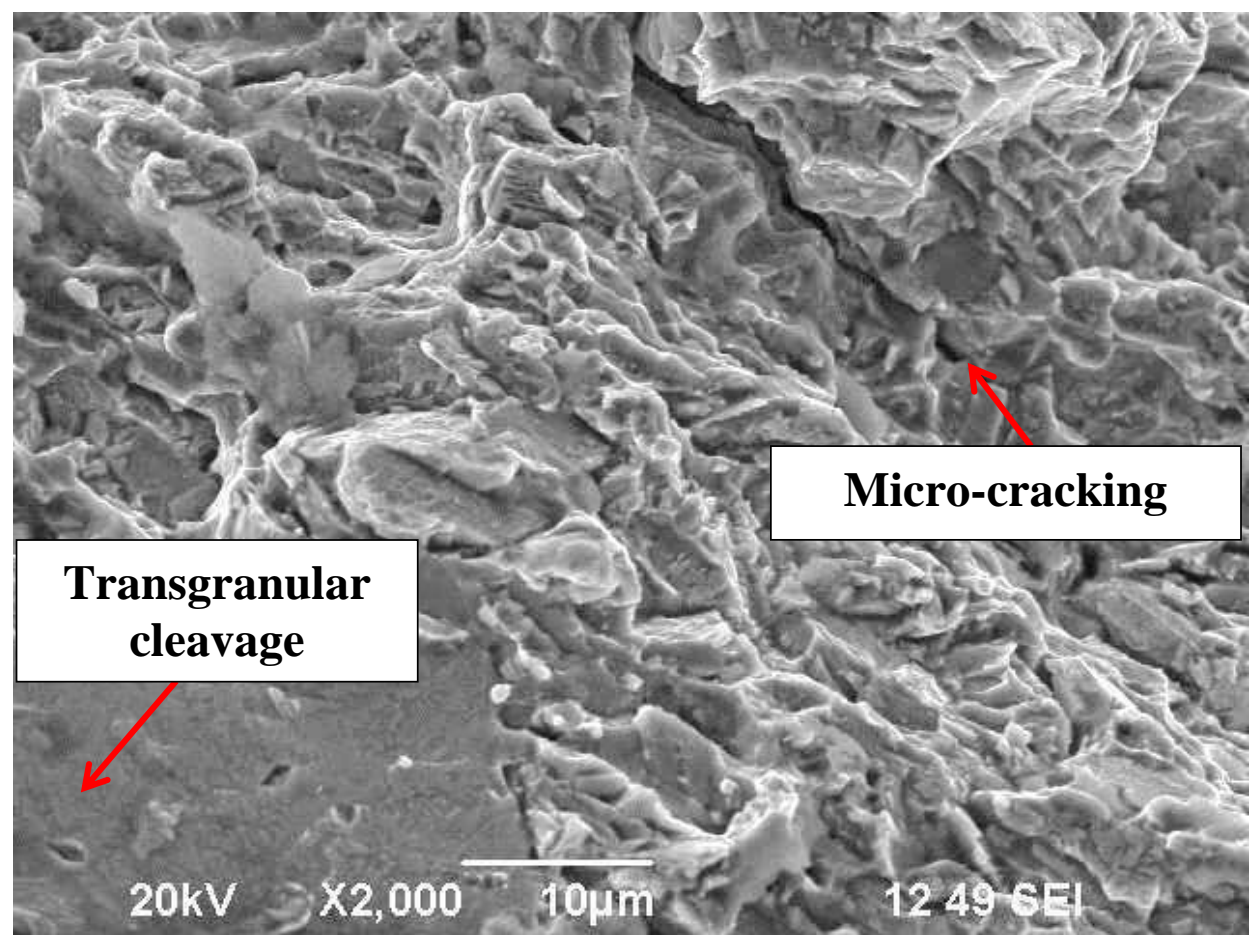

Figure 4: SEM micrograph showing cleavage fracture at Location 2 in Figure 2 for the failed EWA nut from [3] 


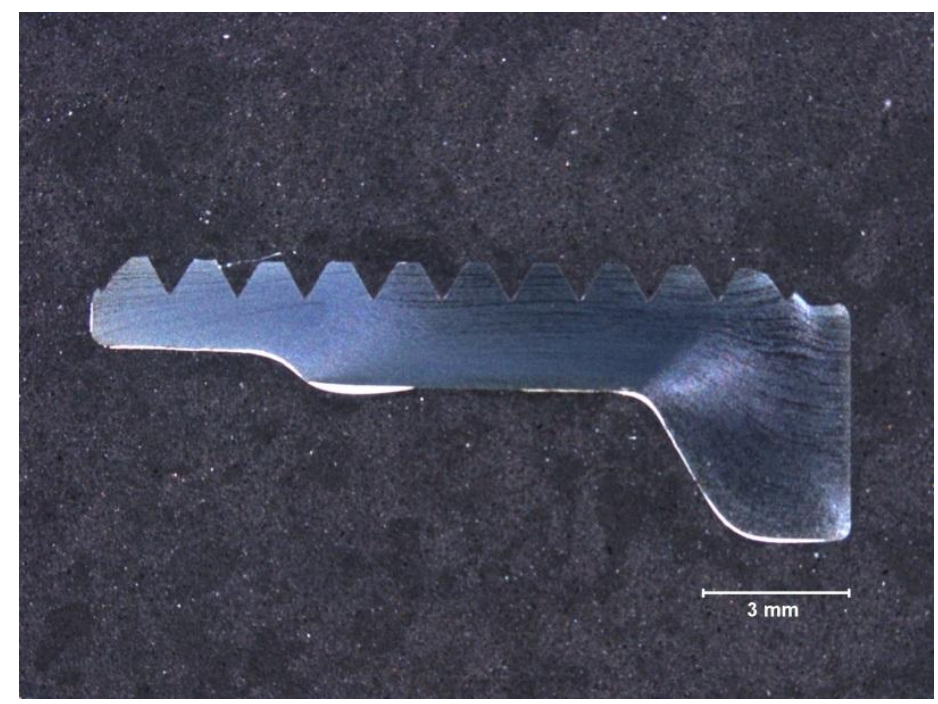

(a)

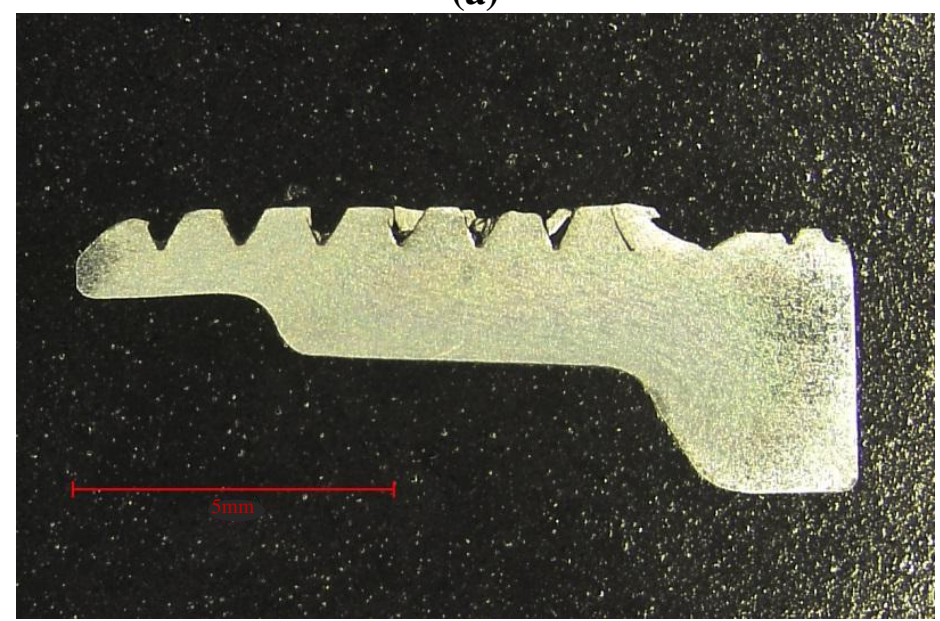

(b)

Figure 5: Comparision stereomicrographs of mounted sections of (a) a nut which failed in the field and (b) a torque test nut which exhibits thread damage due to shanking 


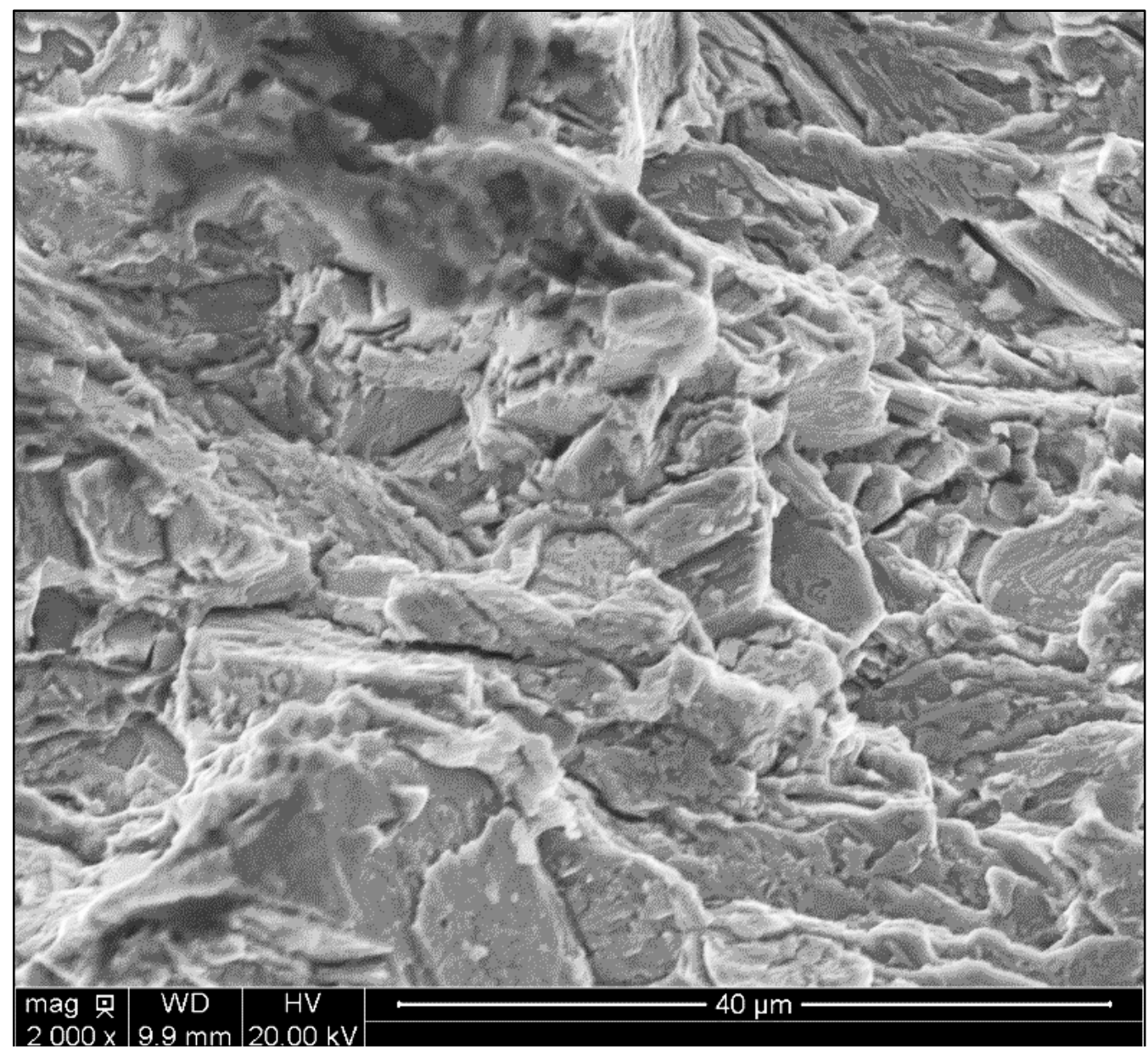

Figure 6: High magnification SEM image of the origin region of an EWA nut fracture showing brittle surface morphology 


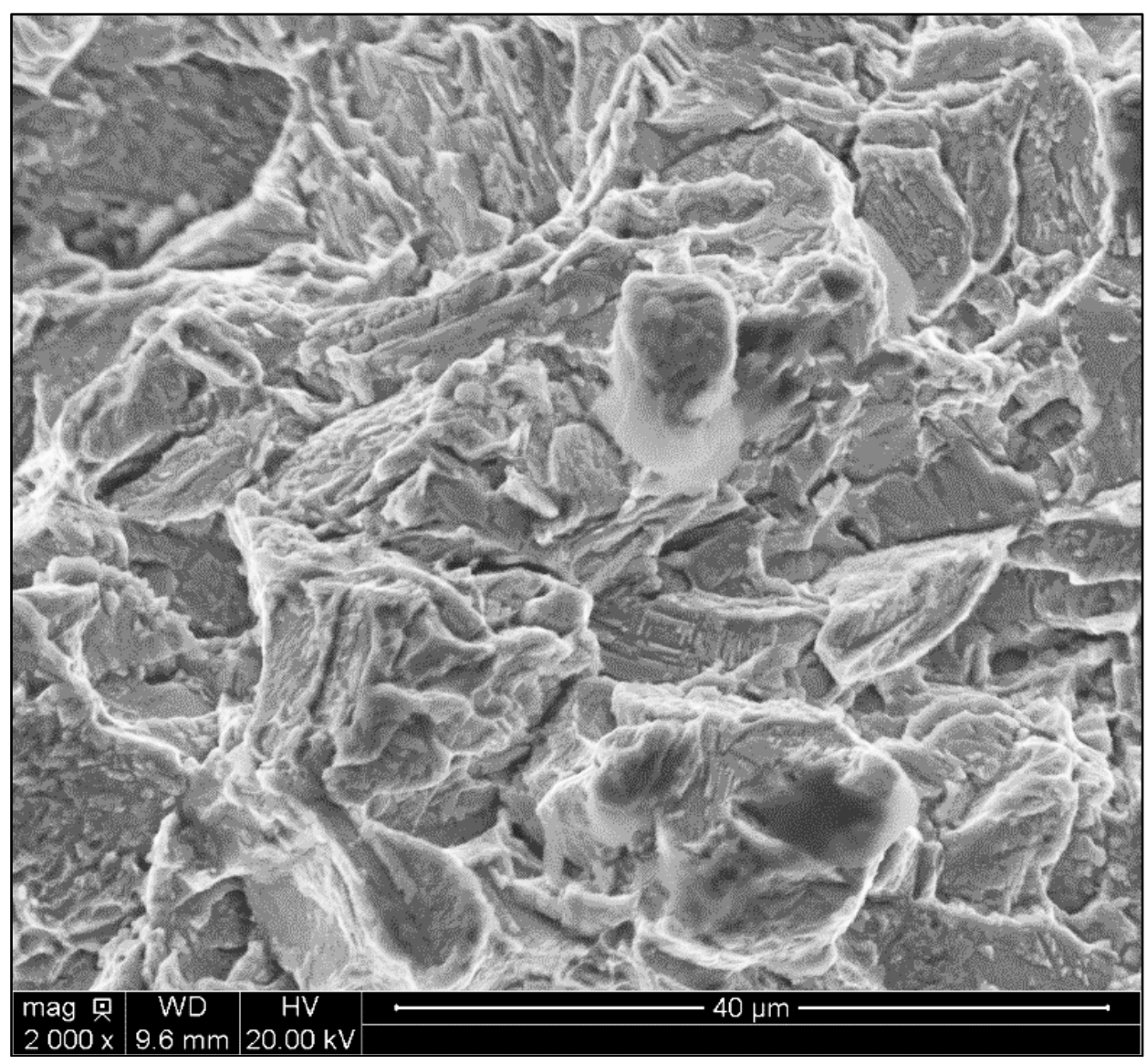

Figure 7: High magnification SEM image of the fracture surface of an EWA nut remote from the origin where secondary cracking is visible 


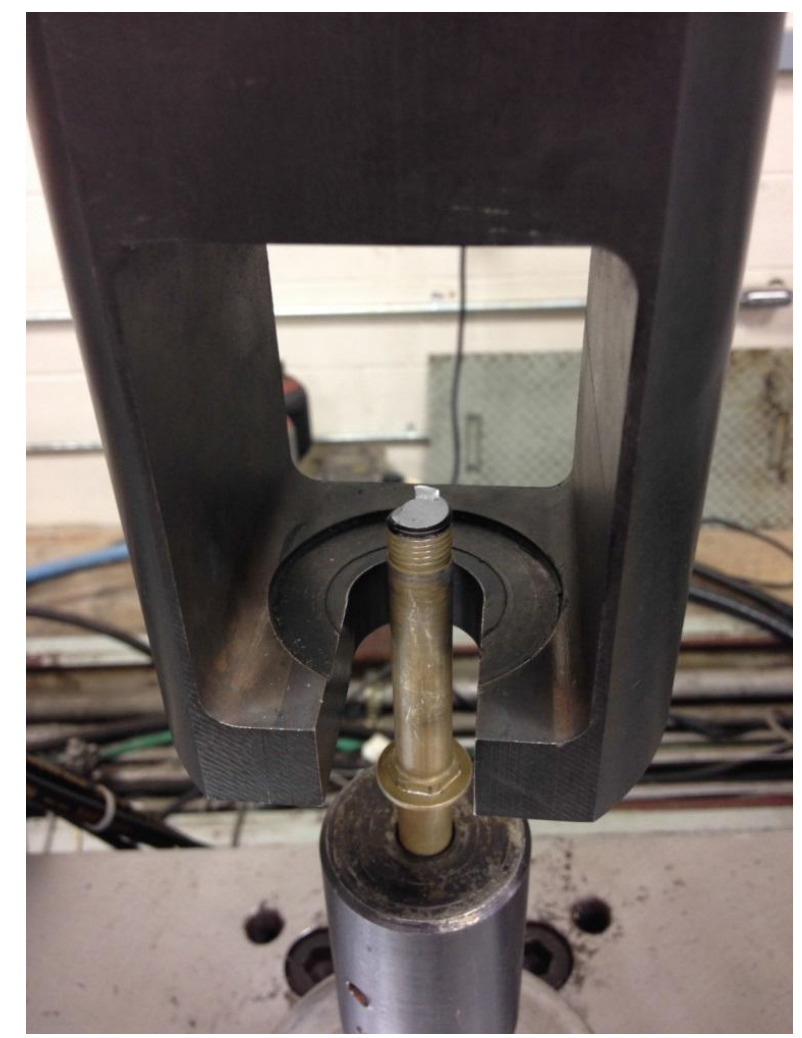

Figure 8: Image of a $\mathbf{- 8}$ nut tensile test with fixturing shown

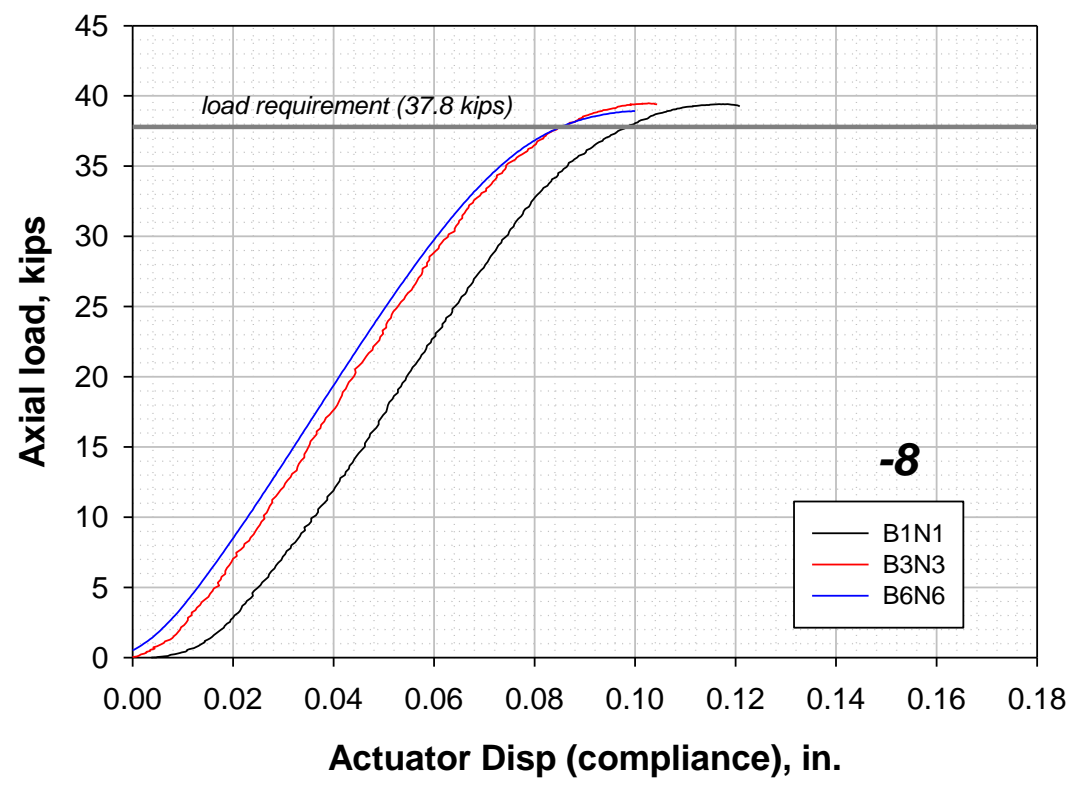

Figure 9: Load versus displacement for the $\mathbf{- 8}$ geometry 


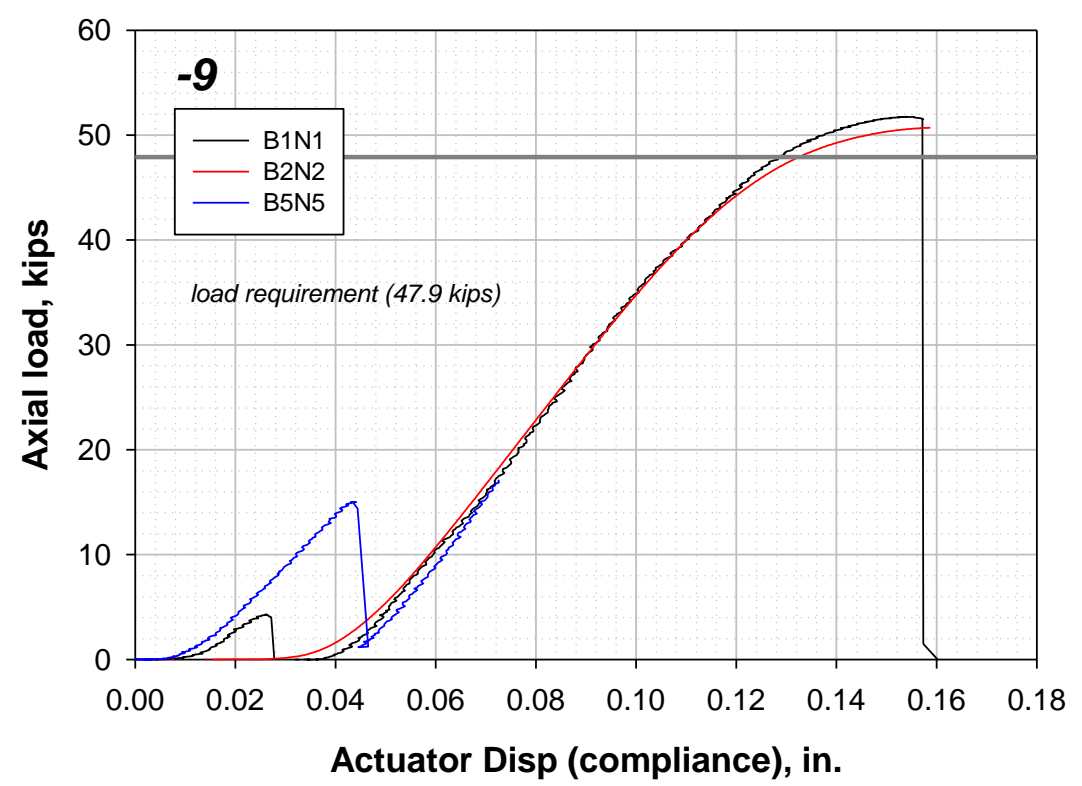

Figure 10: Load versus displacement for the -9 geometry

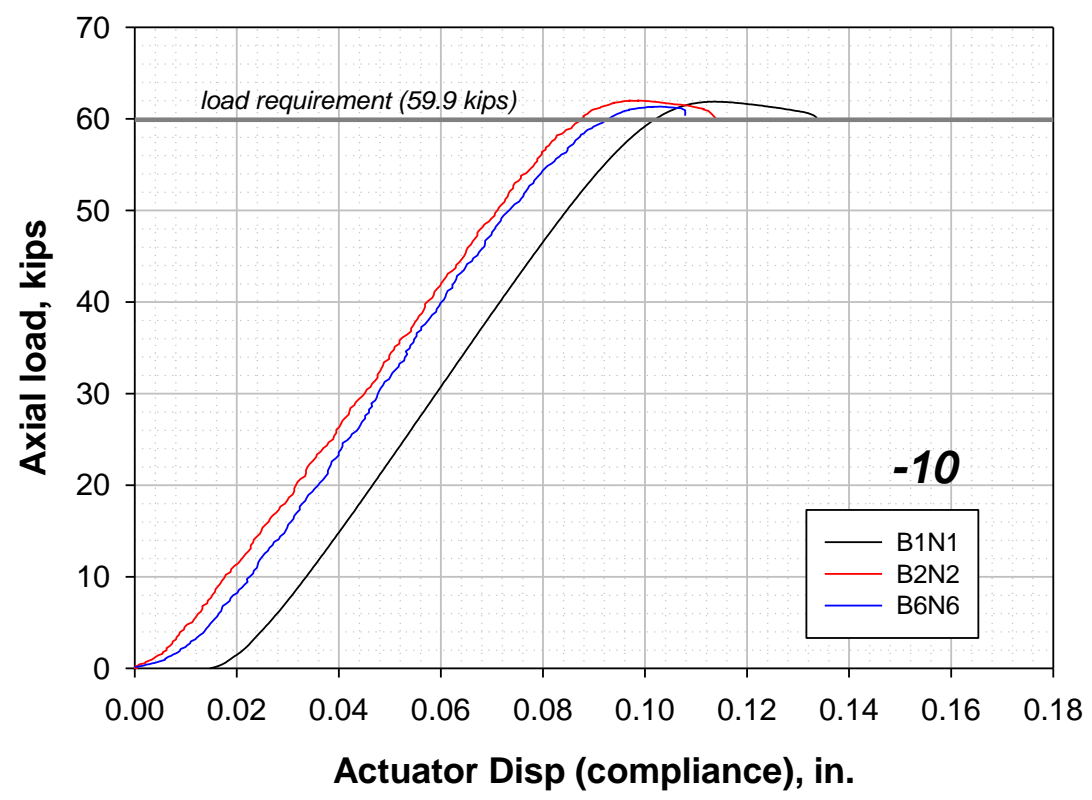

Figure 11: Load versus displacement for the $\mathbf{- 1 0}$ geometry 


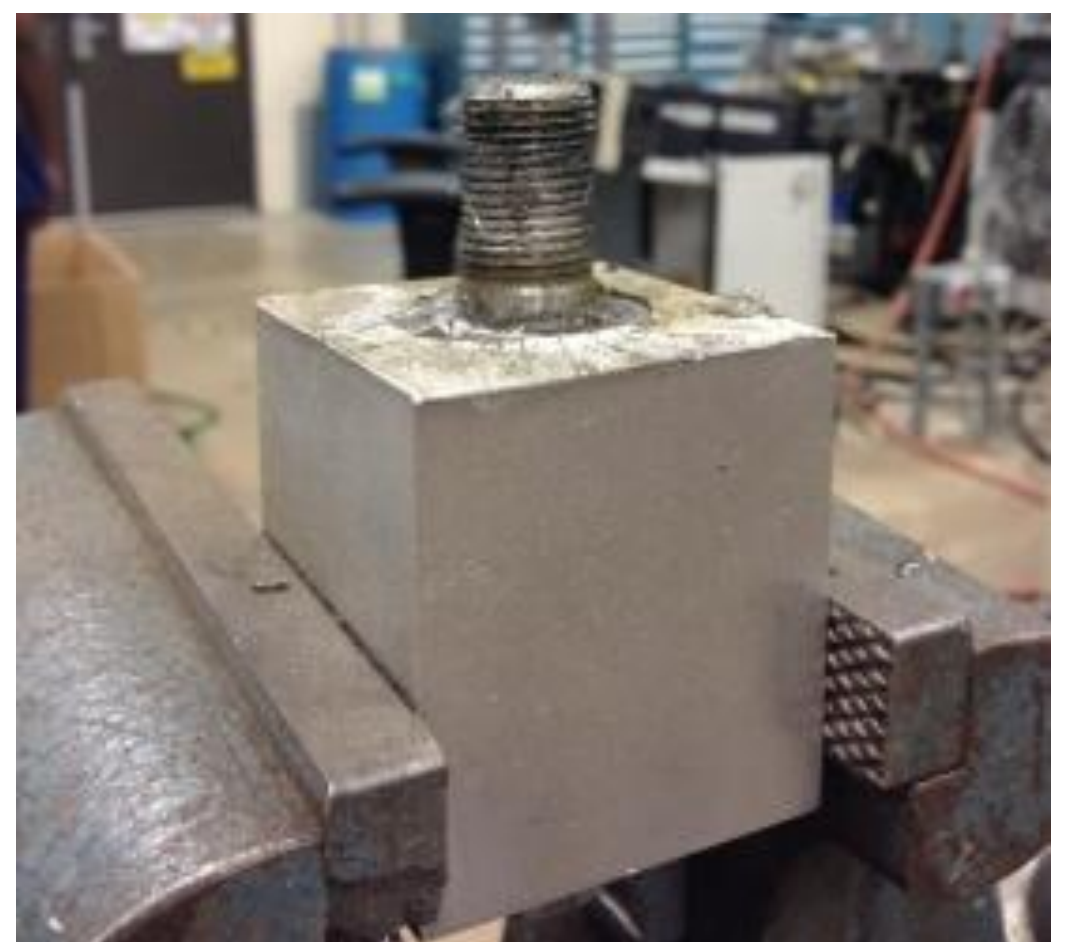

Figure 12: Photo of torque test setup

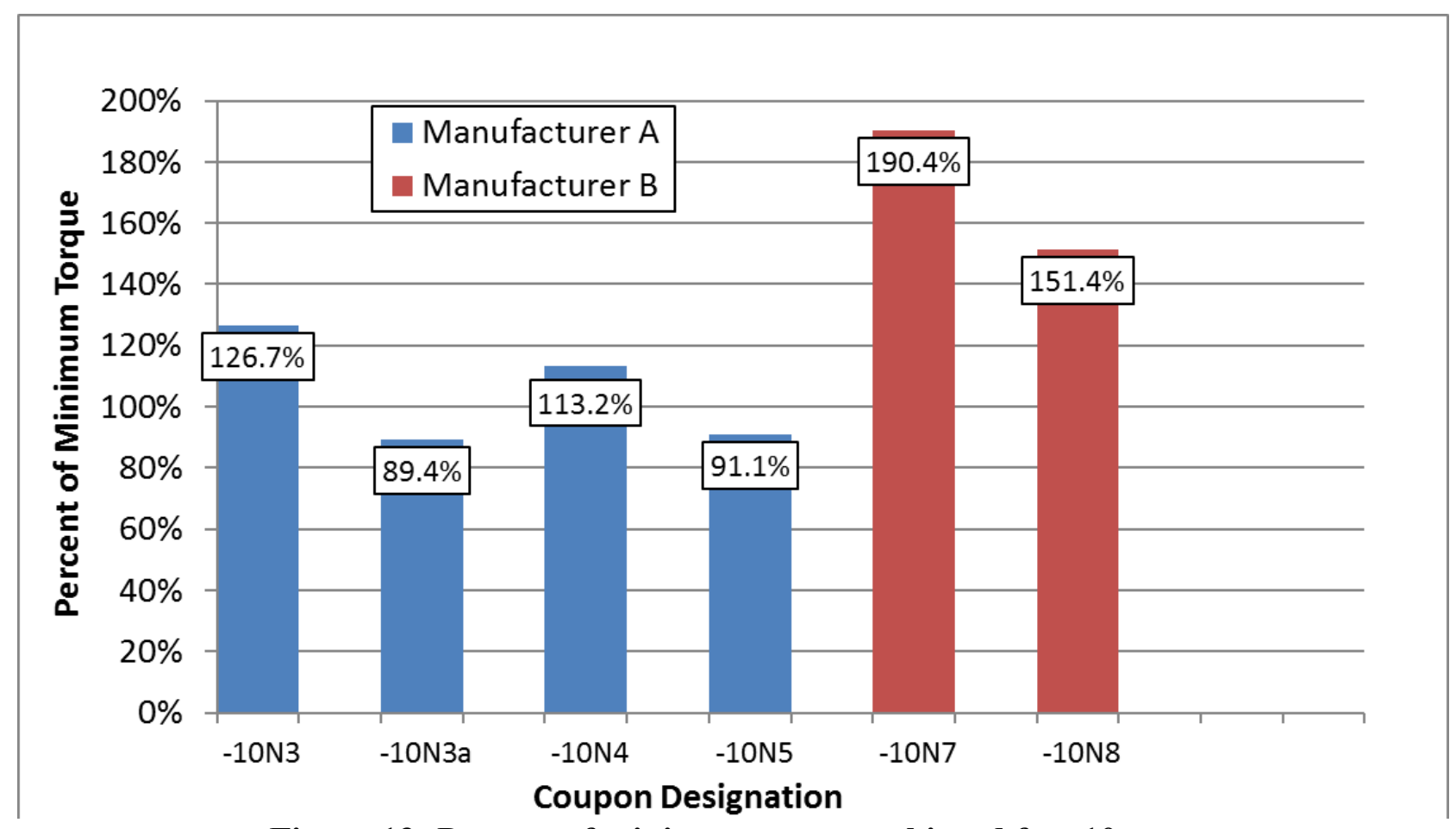

Figure 13: Percent of minimum torque achieved for $\mathbf{- 1 0}$ nuts 


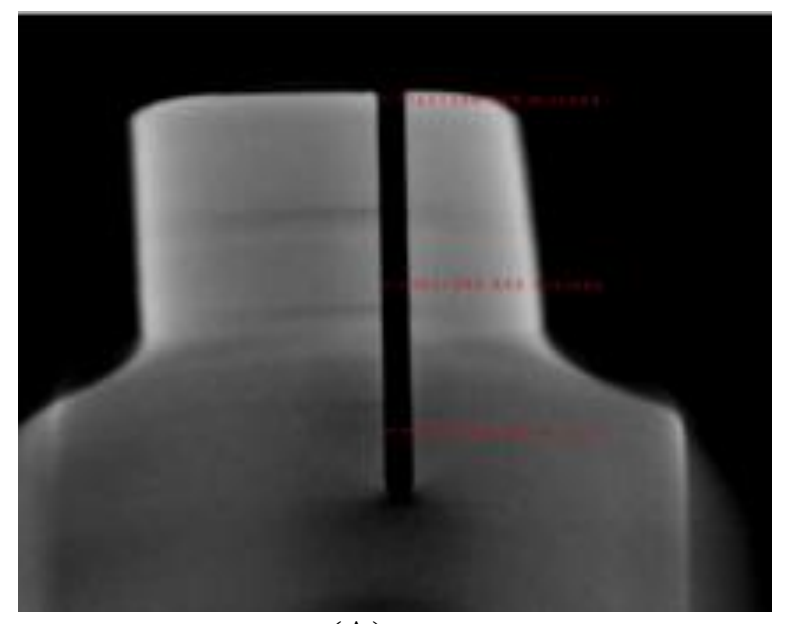

(A)

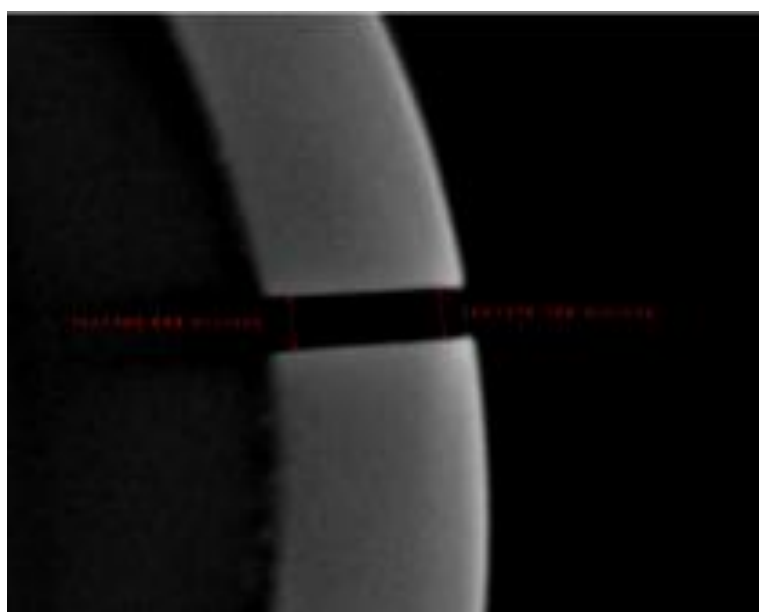

(B)

Figure 14: Generated microCT images for the nut fragment showing (A) axial and (B) transverse views of the notch

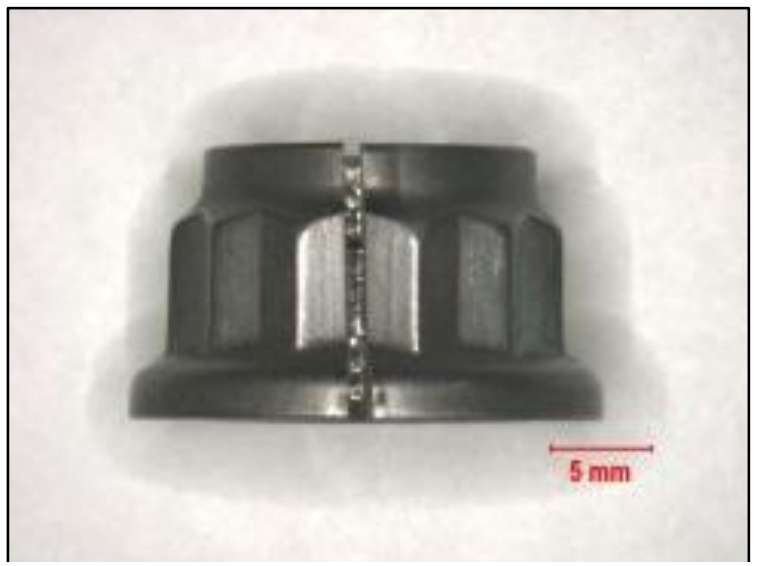

(A)

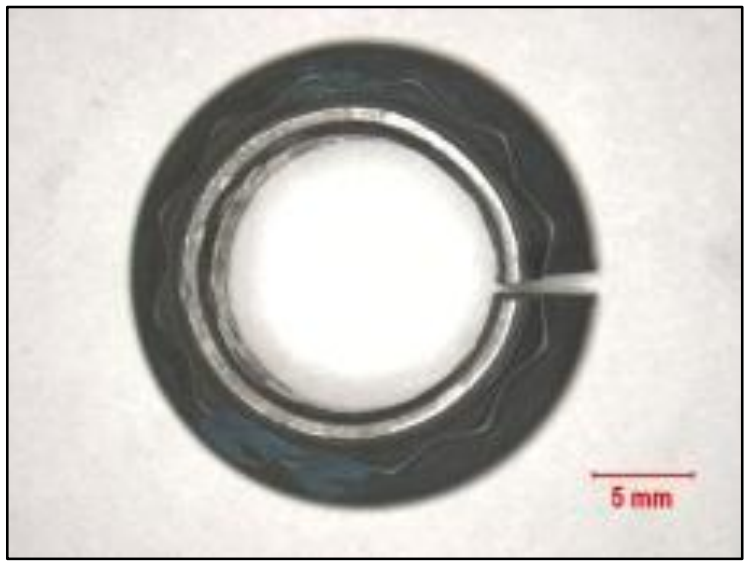

(B)

Figure 15: Stereomicroscope images of the slit -9N1 nut from the (A) side and (B) overhead perspective 


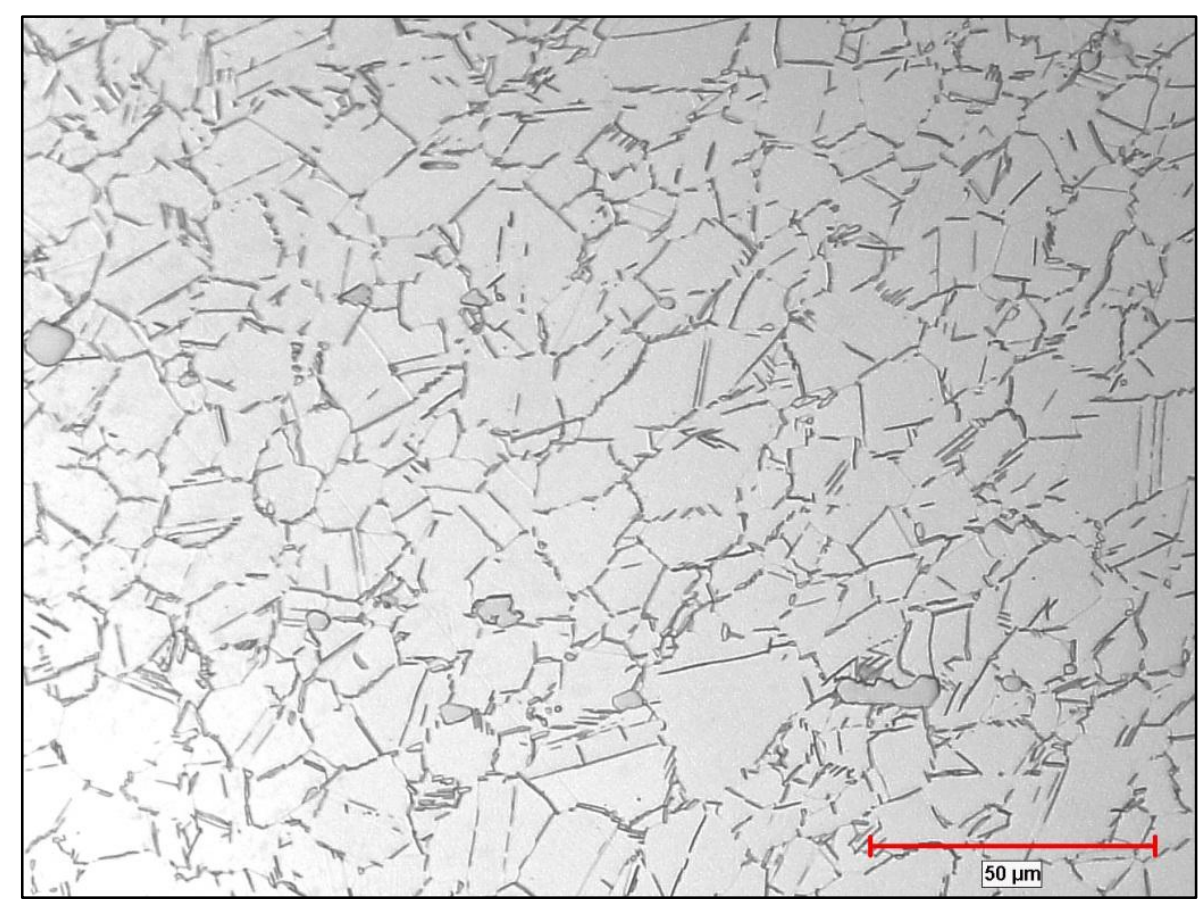

Figure 16: Light micrograph showing representative equiaxed microstructure from the corner region of a -10 nut subjected to EDM slitting

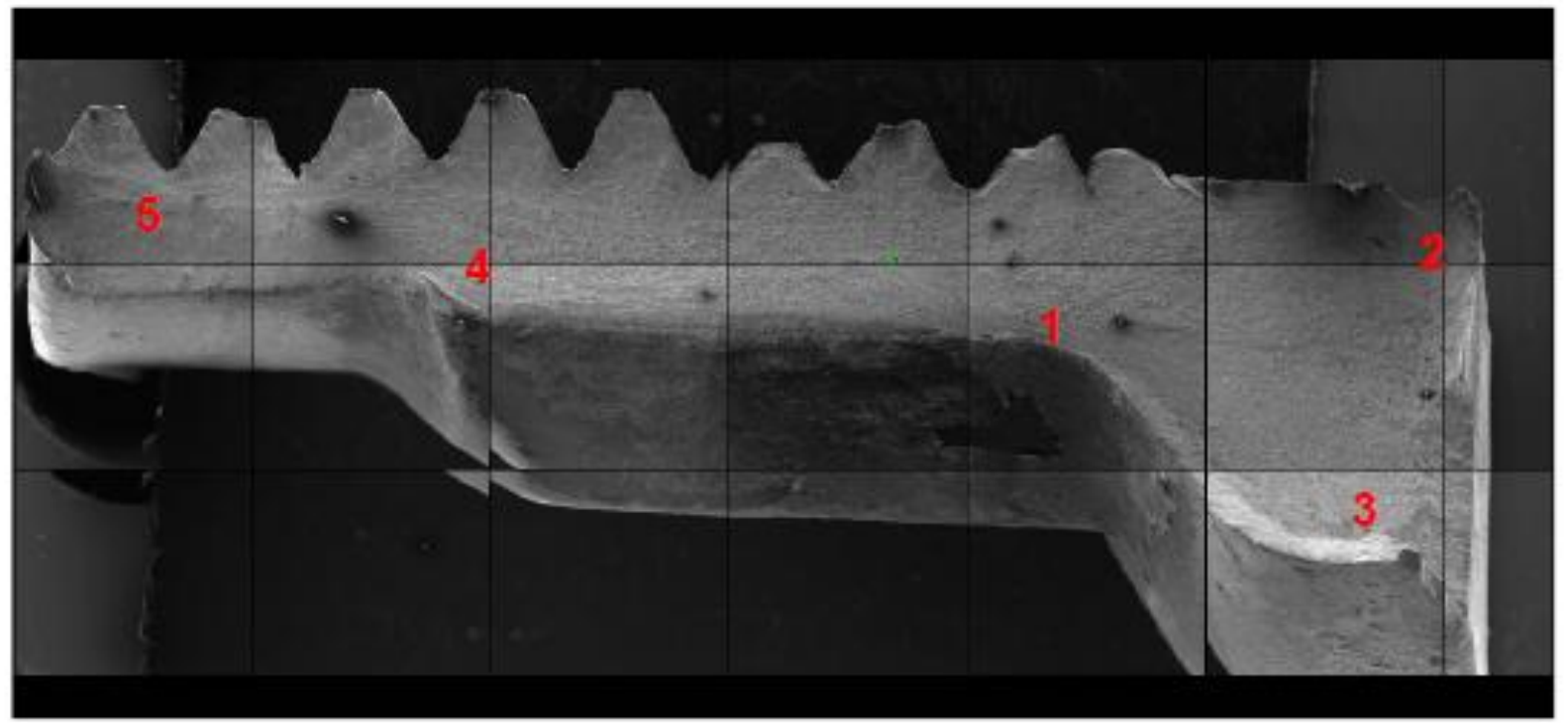

Figure 17: SEM overview image of one side of the -10N4 fracture surface 


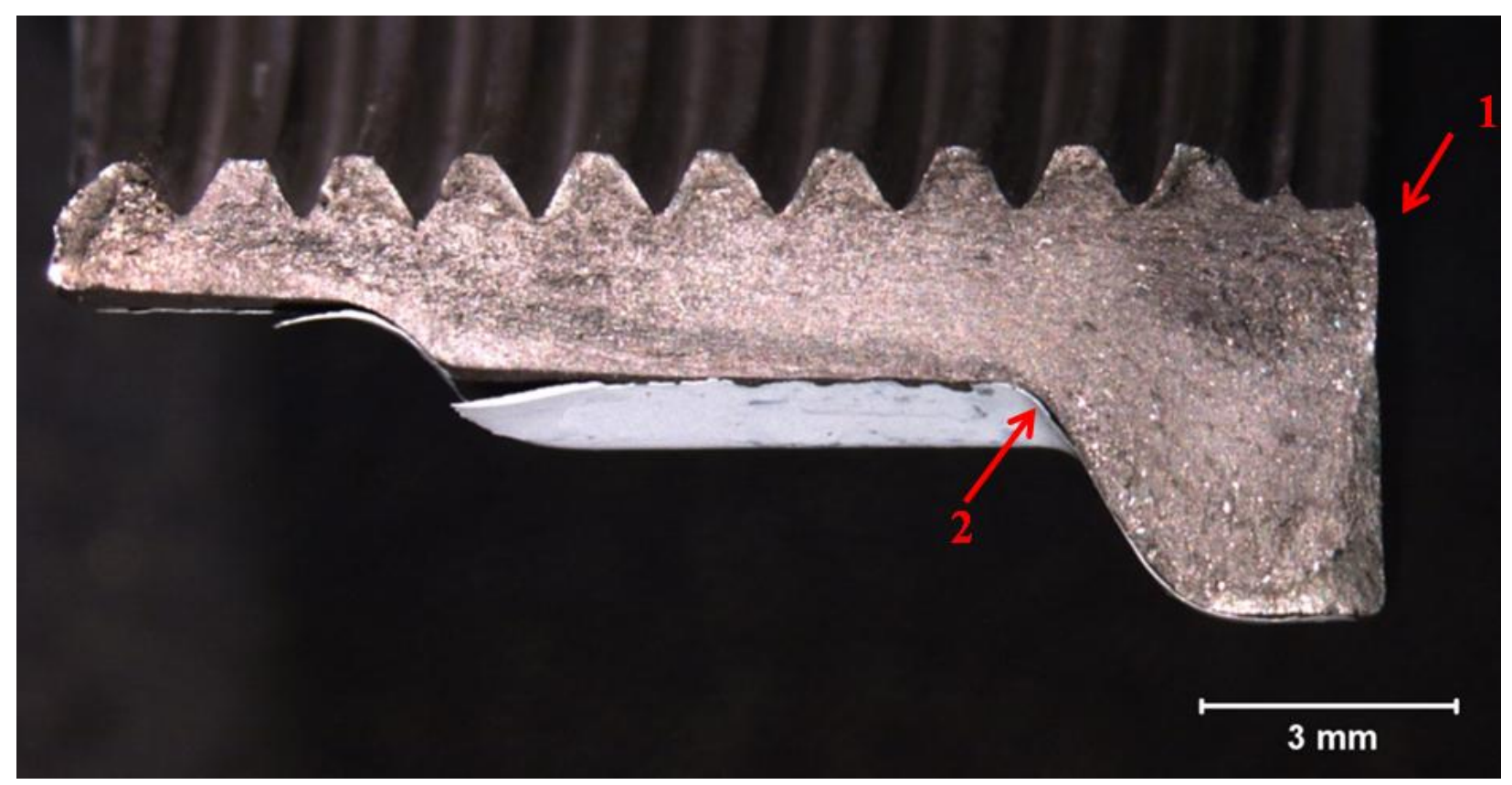

Figure 18: Stereomicroscope image of a trunnon nut fracture surface, indicating the locations of the different fracture origins observed on the various nuts

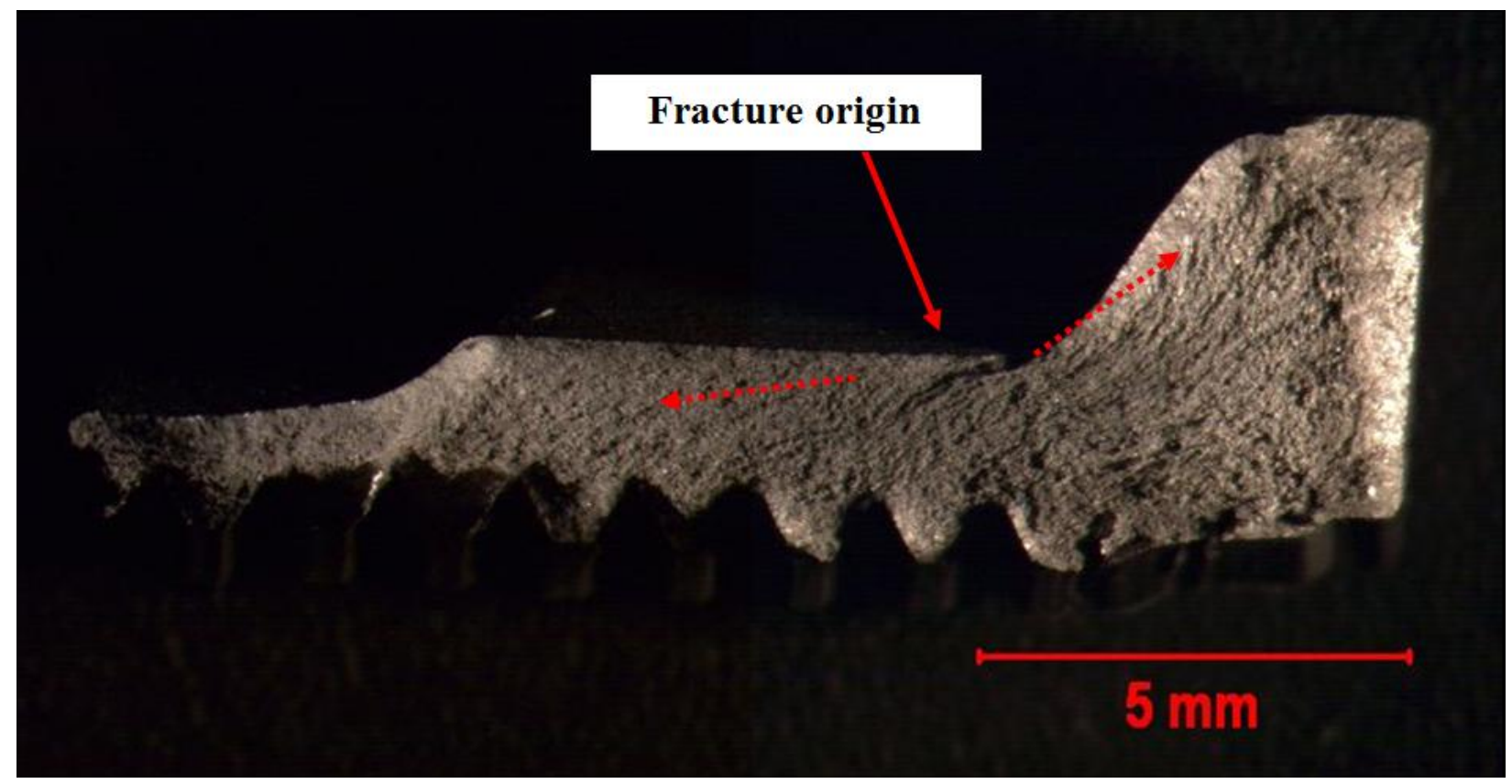

Figure 19. Stereomicroscope images of -10N3a fracture faces post cleaning where dotted lines indicate the direction of fracture propagation 


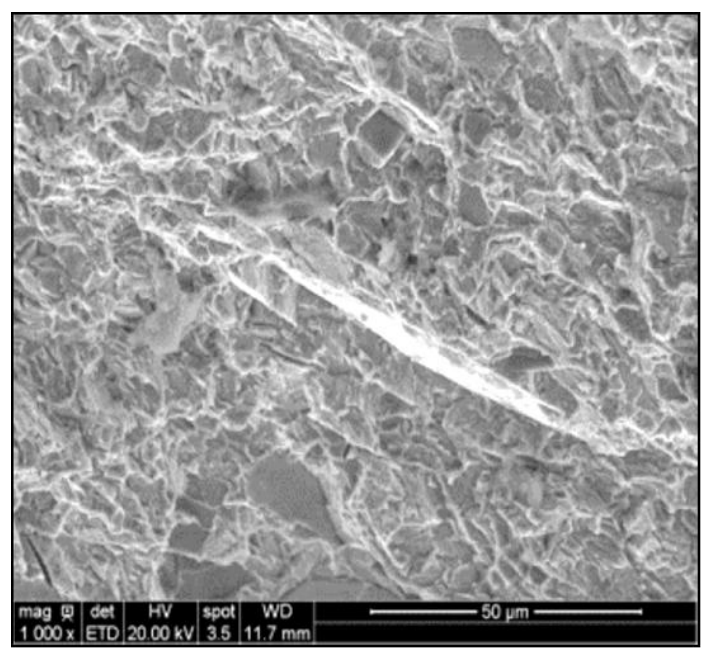

(a)

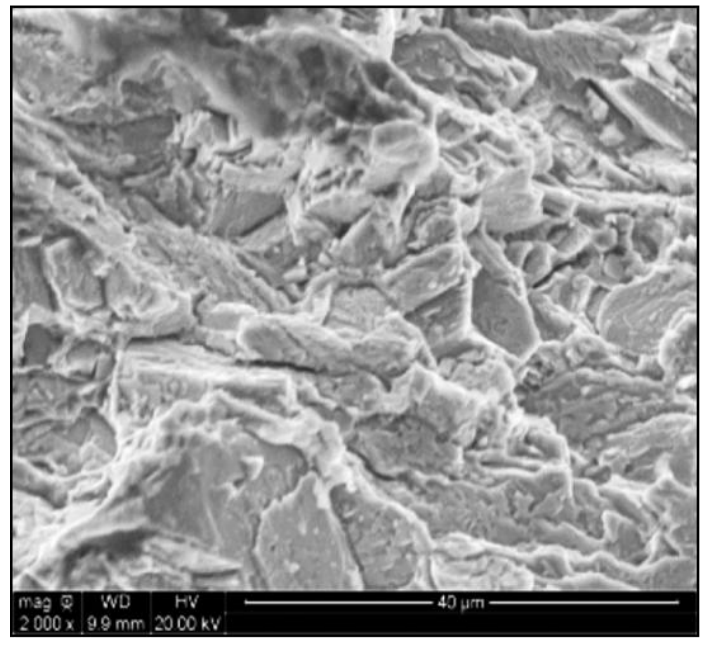

(c)

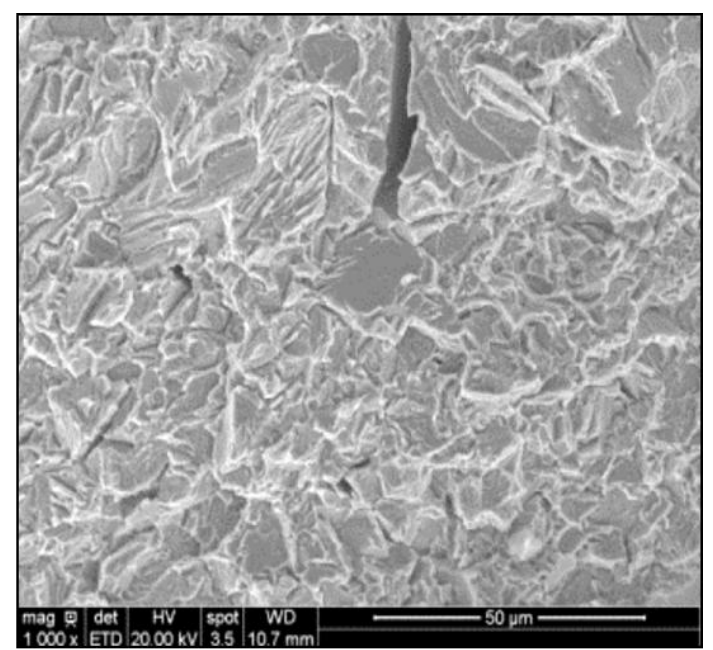

(b)

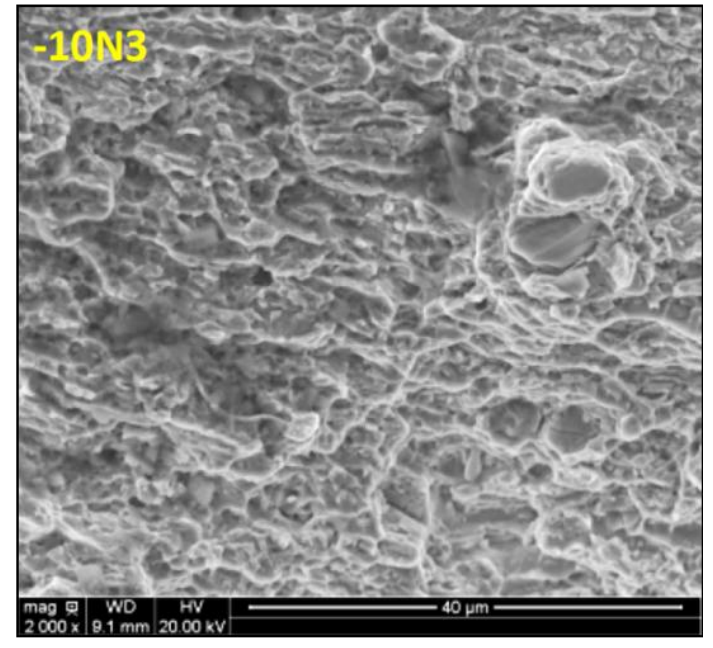

(d)

Figure 20: High magnification SEM images showing the suspected fracture origins of four different nuts. The nuts shown in (a),(b), and (c) were EWA nuts which failed in the field, while the nut shown in (d) was failed in a torque test. The fracture surfaces in (a),(b) and (c) exhibit brittle morphologies, while (d) exhibits mixed mode features. 


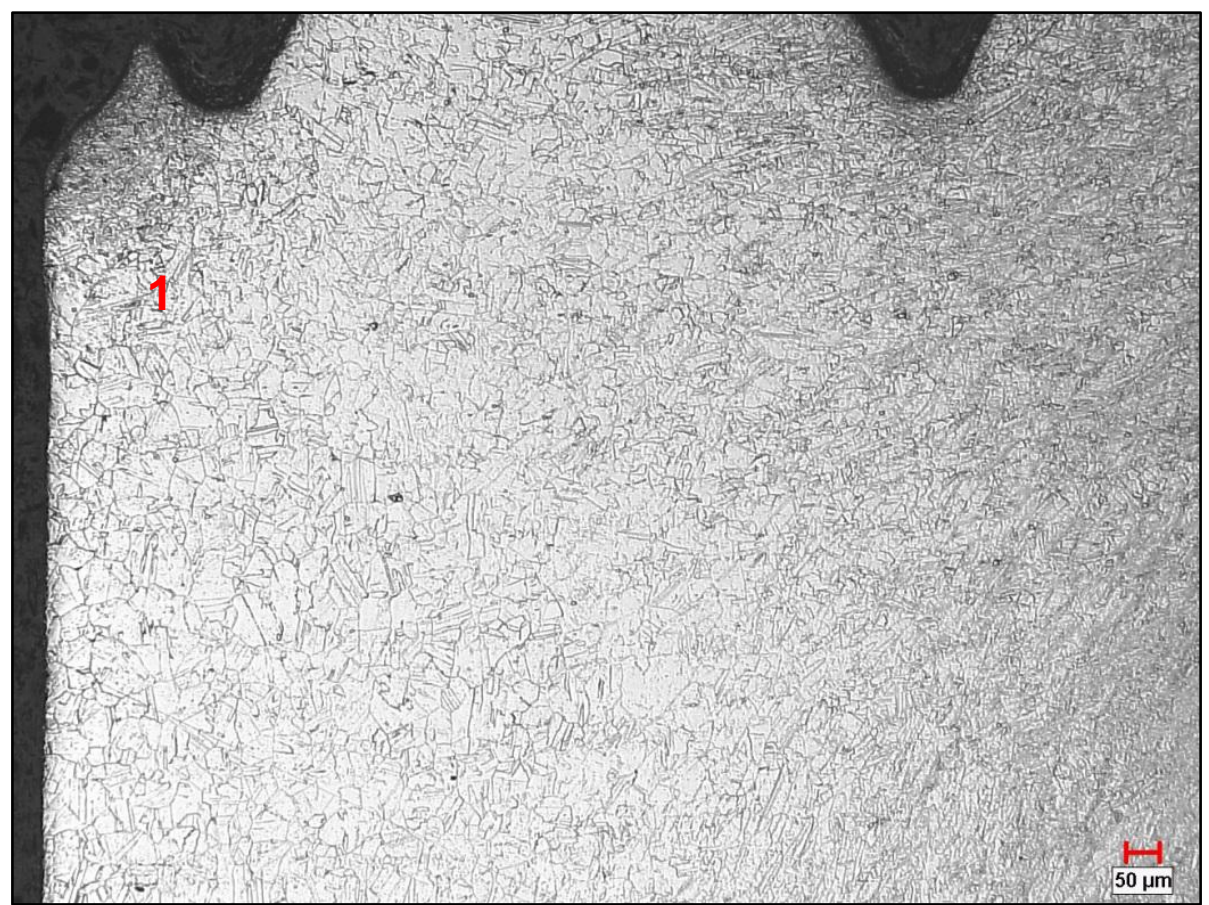

Figure 21. Light micrograph of corner region of sample $-8 \mathrm{N3}$

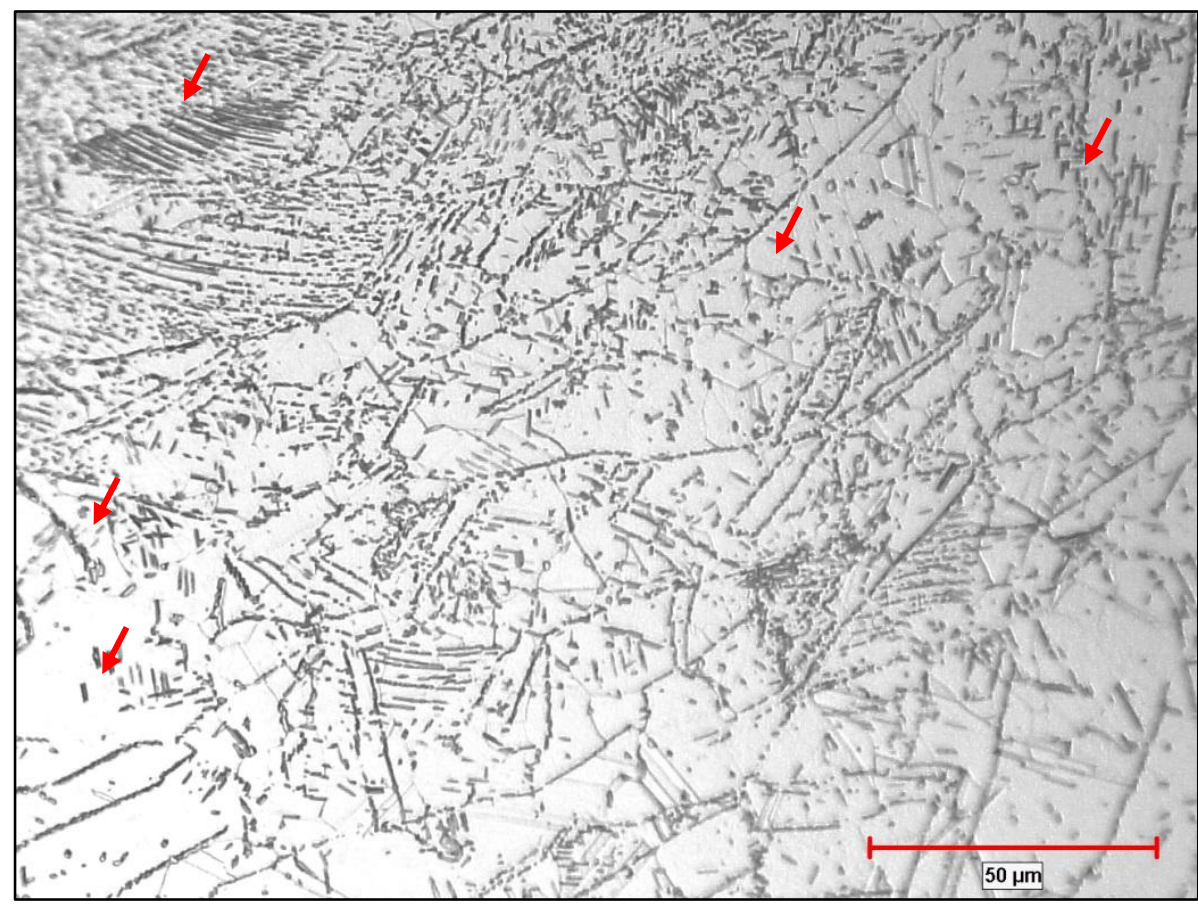

Figure 22. High magnification light micrograph of Location 1 in Figure 21 of sample -8N3 


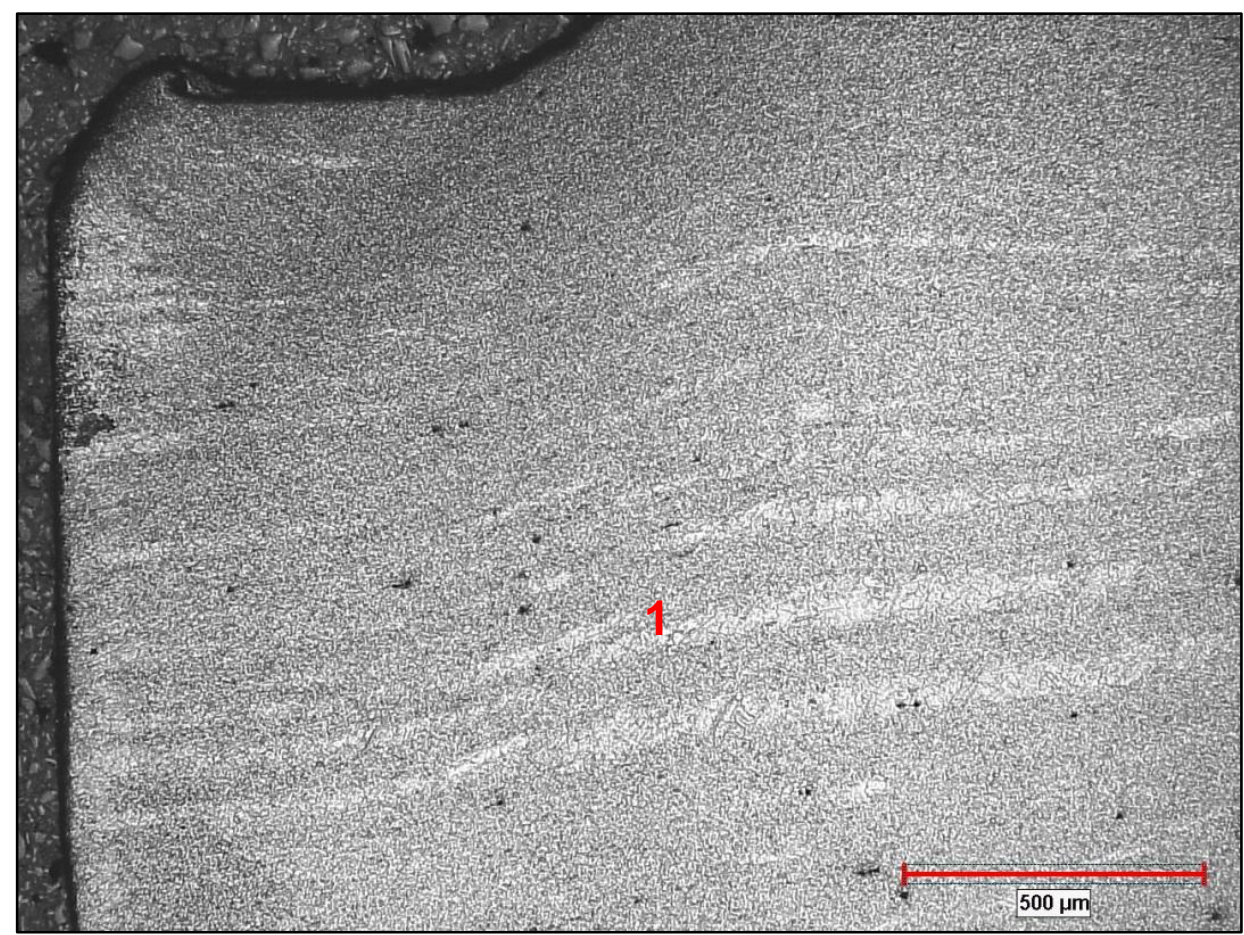

Figure 23: Light micrograph of corner region of sample -9N8

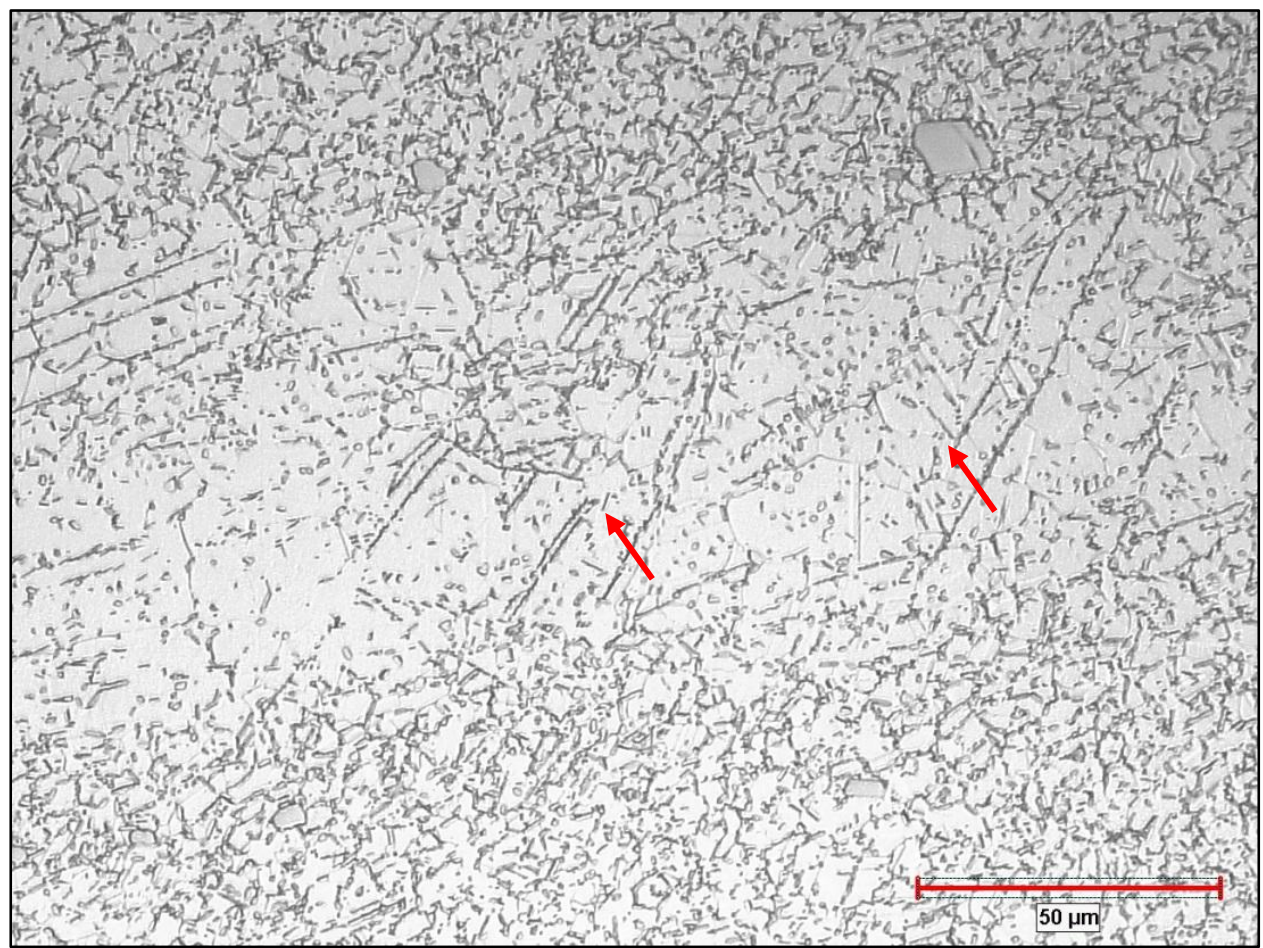

Figure 24: Light micrograph of Location 1 in Figure 23 of sample -9N8 (red arrows indicate delta phase) 


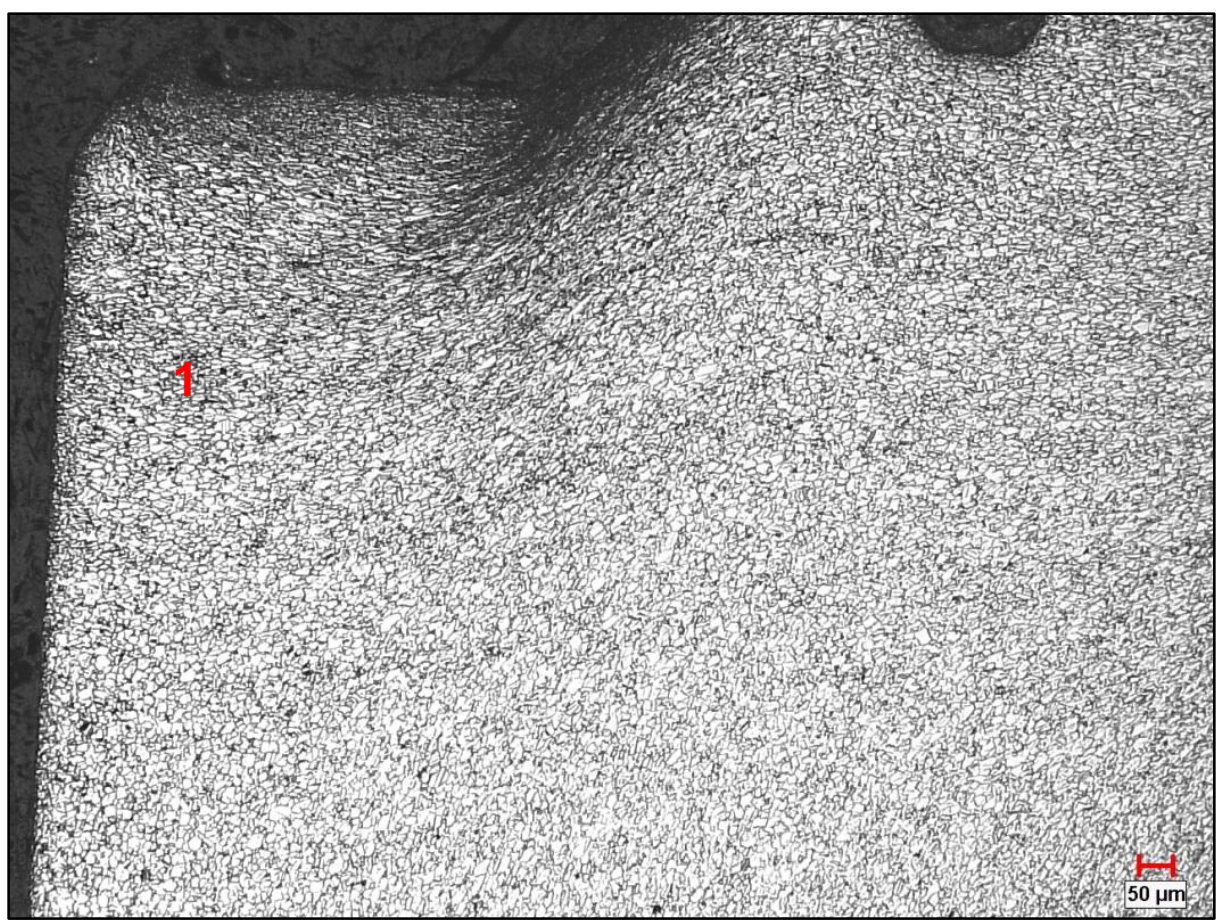

Figure 25: Light micrograph of corner region representative of the -10 tension test nuts

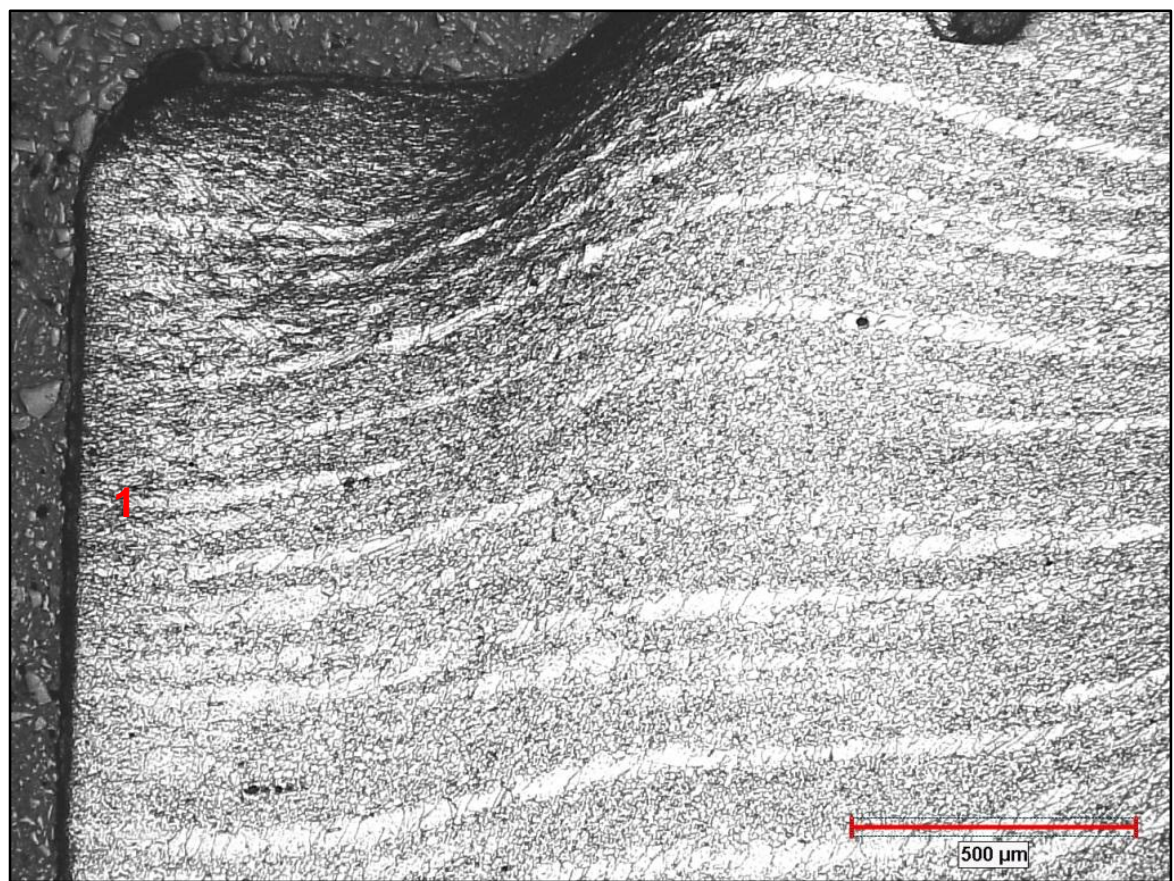

Figure 26: Light micrograph of corner region representative of the $\mathbf{- 1 0}$ torque test nuts 


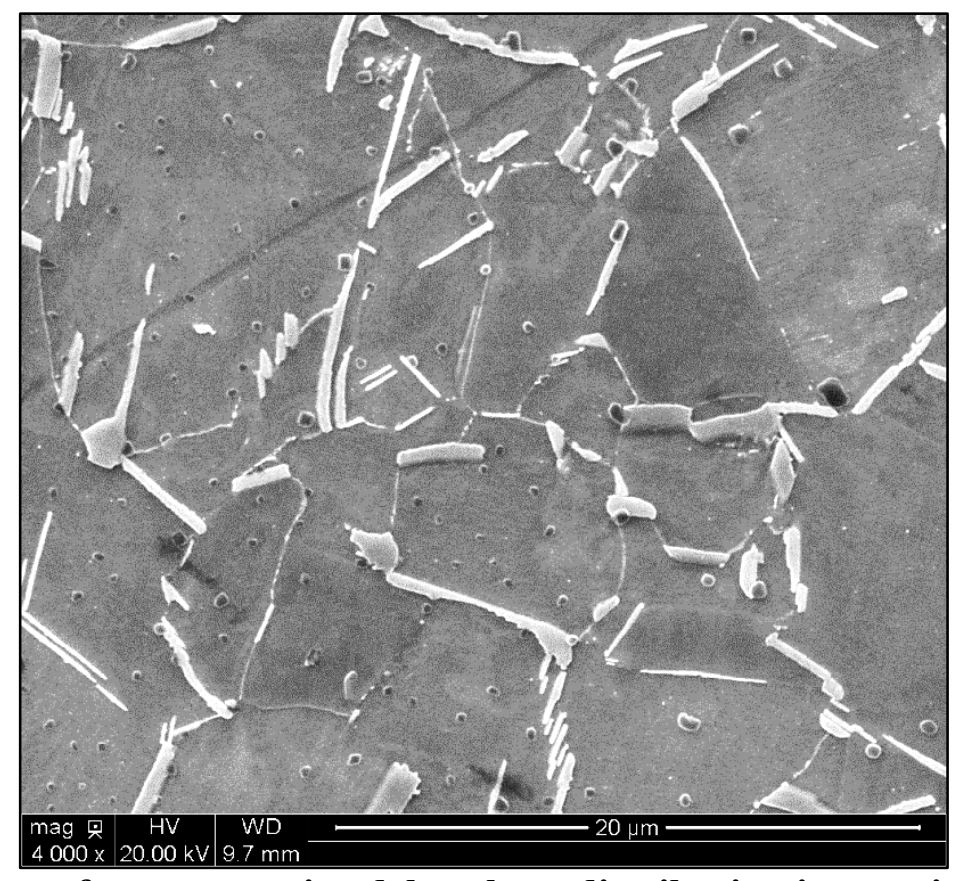

Figure 27: SEM image of representative delta phase distribution in a region of equiaxed grains

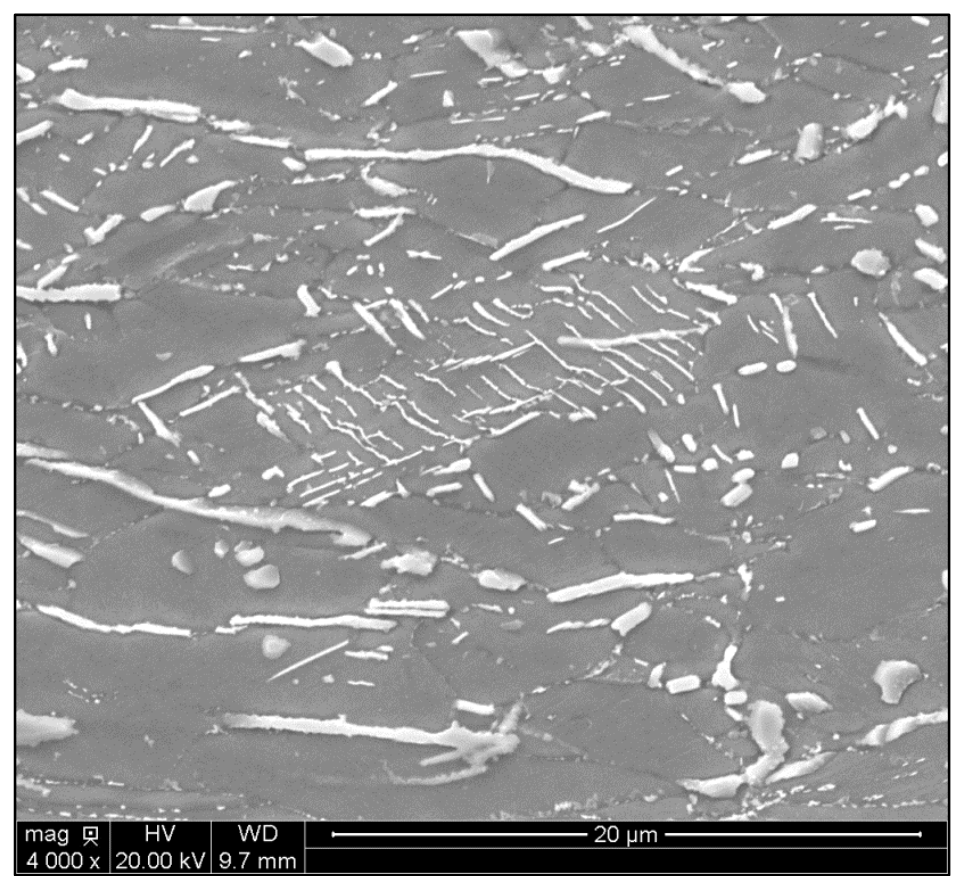

Figure 28: SEM image of representative delta phase distribution in a banded area with a large variation in grain size 

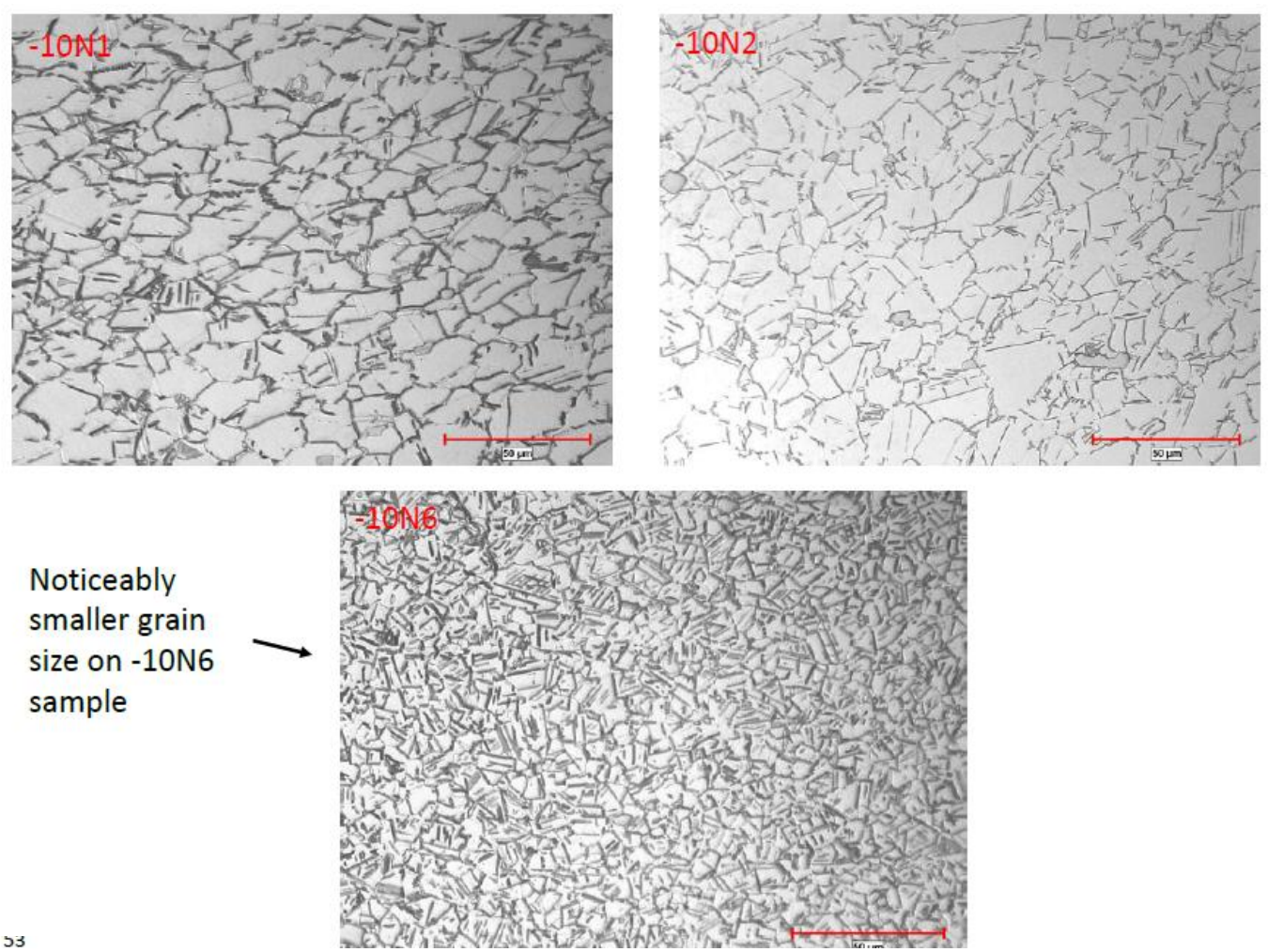

Figure 29: Nut microstructure of corner region showing different grain sizes based on manufacturer for three $\mathbf{- 1 0}$ nuts 